This item was submitted to Loughborough's Research Repository by the author.

Items in Figshare are protected by copyright, with all rights reserved, unless otherwise indicated.

\title{
Majority bargaining for resource division
}

PLEASE CITE THE PUBLISHED VERSION

http://dx.doi.org/10.1007/s10458-015-9290-8

\section{PUBLISHER}

(c) Springer Verlag

\section{VERSION}

AM (Accepted Manuscript)

\section{PUBLISHER STATEMENT}

This work is made available according to the conditions of the Creative Commons Attribution-NonCommercialNoDerivatives 4.0 International (CC BY-NC-ND 4.0) licence. Full details of this licence are available at: https://creativecommons.org/licenses/by-nc-nd/4.0/

\section{LICENCE}

CC BY-NC-ND 4.0

\section{REPOSITORY RECORD}

Fatima, Shaheen, and Michael Wooldridge. 2019. "Majority Bargaining for Resource Division". figshare. https://hdl.handle.net/2134/16733. 


\title{
Majority Bargaining for Resource Division
}

\author{
Shaheen Fatima • Michael Wooldridge
}

the date of receipt and acceptance should be inserted later

\begin{abstract}
We address the problem of how a set of agents can decide to share a resource, represented as a unit-sized pie. The pie can be generated by the entire set but also by some of its subsets. We investigate a finite horizon non-cooperative bargaining game, in which the players take it in turns to make proposals on how the resource should for this purpose be allocated, and the other players vote on whether or not to accept the allocation. Voting is modelled as a Bayesian weighted voting game with uncertainty about the players' weights. The agenda, (i.e., the order in which the players are called to make offers), is defined exogenously. We focus on impatient players with heterogeneous discount factors. In the case of a conflict, (i.e., no agreement by the deadline), no player receives anything. We provide a Bayesian subgame perfect equilibrium for the bargaining game and conduct an ex-ante analysis of the resulting outcome. We show that the equilibrium is unique, computable in polynomial time, results in an instant Pareto optimal outcome, and, under certain conditions provides a foundation for the core and also the nucleolus of the Bayesian voting game. In addition, our analysis leads to insights on how an individual's bargained share is influenced by his position on the agenda. Finally, we show that, if the conflict point of the bargaining game changes, then the problem of determining the non-cooperative equilibrium becomes NP-hard even under the perfect information assumption. Our research also reveals how this change in conflict point impacts on the above mentioned results.
\end{abstract}

Shaheen Fatima

University of Loughborough

Loughborough, UK

E-mail: S.S.Fatima@lboro.ac.uk

Michael Wooldridge

University of Oxford

Oxford, UK

E-mail: Michael.Wooldridge@cs.ox.ac.uk 


\section{Introduction}

We are concerned with one of the fundamental questions in multi-agent systems: There is a set $A$ of agents that comprise the system and there is resource which we assume is a unit-sized divisible pie. The pie can be generated by more than one subset (i.e., coalition) $C \subseteq A$ and represents the joint gain that members of $C$ can produce together. The problem then is to decide how to divide the pie between the players in $A$. Conflict arises because each agent prefers to maximize its own share of the pie.

There are two key approaches for resolving such a conflict $[37,33,28]$. One approach is to model the situation as a cooperative game and distribute the pie as per its equilibrium, and the other is to model the scenario as a non-cooperative bargaining game, and distribute the pie as per its equilibrium solution. A study of the relation between the solutions generated by these two approaches forms the Nash program [34]. In this paper, we follow the Nash program in the context of multilateral bargaining over a unit-sized divisible pie.

Over the years, a number of non-cooperative models of multilateral bargaining grew out of Rubinstein's bilateral ${ }^{1}$ bargaining game [29] in which the players decide how to split a unit-sized pie by exchanging a series of offers and counter-offers. These include $[2,35,11,10]$ and the focus of this research was on addressing issues such as determining their equilibria and studying the computational and economic properties of equilibrium outcomes. However, the scope of the results of this research is limited since they are based on assumptions such as perfect information, no deadline or a very constrained bargaining deadline, no time discounting or all the players having a common discount factor, or the agenda (the term 'agenda' refers to the order in which the players are called to make proposals) being random (see Section 8 for details). In addition, there has been no detailed analysis of the influence of bargaining parameters such as the agenda and the conflict point on the equilibrium outcome. Given this state of art, our aims are as follows.

\section{Aims:}

1. One of our aims is to extend the scope of the existing results by dropping the above mentioned assumptions. Specifically, we consider a new and more realistic bargaining context with a flexible deadline, heterogeneous discount factors (i.e., discount factors may differ across the agents), imperfect information, and an exogenously defined agenda. As we will show, these considerations lead to differences in terms of the type (i.e., stationary or subgame perfect) of equilibrium but also in terms of the resulting equilibrium shares.

2. Our second aim is to analyze how a player's position on the agenda influences his equilibrium share, and how the conflict point of a bargaining game influences the complexity of computing its non-cooperative equilibrium and how it influences the relation between the non-cooperative equilibrium and the core/nucleolus of the Bayesian voting game) in the above context.

\footnotetext{
1 For bilateral bargaining itself, Rubinstein's bargaining game has been analyzed in various settings that differ in terms of the information available to the bargainers. These include $[15,7]$ but a more complete discussion of this literature can be found in [14].
} 


\begin{tabular}{|c|c|c|c|}
\hline & Research Question & Research Result & Type of result \\
\hline 1 & What is the type of bargaining equilibrium? & Subgame perfect & $\begin{array}{c}\text { Theoretical proof } \\
\text { Theorems } 1,3 \text { and } 13\end{array}$ \\
\hline 2 & $\begin{array}{c}\text { What are the properties of the equilibrium } \\
\text { agreement? }\end{array}$ & $\begin{array}{l}\text { The agreement is unique, } \\
\text { instant, and Pareto optimal }\end{array}$ & $\begin{array}{c}\text { Theoretical proof } \\
\text { Theorems } 1 \text { and } 3 \text {, and } \\
\text { Observation } 2\end{array}$ \\
\hline 3 & $\begin{array}{l}\text { What is the time complexity of } \\
\text { computing equilibrium? }\end{array}$ & $\begin{array}{l}\text { Polynomial time } \\
\text { NP-hard }\end{array}$ & $\begin{array}{c}\text { Theoretical proof } \\
\text { Theorems 2, 4, and } 12\end{array}$ \\
\hline 4 & $\begin{array}{l}\text { Which players get a non-zero share } \\
\text { in the pie? }\end{array}$ & $\begin{array}{l}\text { Regardless of the agenda, only } \\
\text { the players in }\left\{A_{1}\right\} \cup Z \\
\text { get a non-zero share }\end{array}$ & $\begin{array}{c}\text { Theoretical proof } \\
\text { Theorem 14, and } \\
\text { Observations } 1 \text { and } 3\end{array}$ \\
\hline 5 & $\begin{array}{c}\text { What is the relation between the bargaining } \\
\text { equilibrium and the ex-ante core } \\
\text { of the Bayesian WVG? }\end{array}$ & $\begin{array}{l}\text { The bargained agreement } \\
\text { may or may not belong to the core } \\
\text { (see the decision tree of Figure 1) } \\
\text { The bargained agreement } \\
\text { does not belong to the core }\end{array}$ & $\begin{array}{c}\text { Theoretical proof } \\
\text { Theorems 5, 6, and } 17\end{array}$ \\
\hline 6 & $\begin{array}{c}\text { What is the relation between the bargaining } \\
\text { equilibrium and the ex-ante nucleolus } \\
\text { of the Bayesian WVG? }\end{array}$ & $\begin{array}{l}\text { The bargained agreement } \\
\text { may or may not be the nucleolus } \\
\text { (see the decision tree of Figure 2) } \\
\text { The bargained agreement } \\
\text { is not the nucleolus }\end{array}$ & $\begin{array}{l}\text { Theoretical proof } \\
\text { Theorems } 7 \text { to } 9 \text {, and } 18\end{array}$ \\
\hline 7 & $\begin{array}{l}\text { What happens to the shares of the } \\
\text { player's in }\left\{A_{1}\right\} \cup Z \text { as we move } \\
\text { from the first to the last position on } \\
\text { the agenda? }\end{array}$ & $\begin{array}{c}\text { The shares decrease monotonically } \\
\text { from the first to the last mover if the } \\
\text { discount factor lies in the interval }\left(0, \frac{1}{2}\right), \\
\text { and outside this interval, monotonicity } \\
\text { may be lost }\end{array}$ & $\begin{array}{c}\text { Theoretical proof } \\
\text { and simulations } \\
\text { Theorems } 10 \text { and } 15, \\
\text { and } \\
\text { Observation } 4\end{array}$ \\
\hline 8 & $\begin{array}{l}\text { What is the best agenda position } \\
\text { for a non-veto player }\end{array}$ & $\begin{array}{l}\text { It is best for him to be } \\
\text { the first mover }\end{array}$ & $\begin{array}{c}\text { Theoretical proof } \\
\text { Observation } 5\end{array}$ \\
\hline 9 & $\begin{array}{l}\text { What is the best agenda position } \\
\text { for a patient (i.e., with a discount } \\
\text { factor of one) veto player? }\end{array}$ & $\begin{array}{l}\text { It is best for him to be the last } \\
\text { veto player on the agenda }\end{array}$ & $\begin{array}{c}\text { Theoretical proof } \\
\text { Observation } 6\end{array}$ \\
\hline 10 & $\begin{array}{l}\text { What is the best agenda position } \\
\text { for an impatient (i.e., with discount } \\
\text { factor 'sufficiently' close to zero) veto player? } \\
\text { See Observation } 7 \text { for the meaning } \\
\text { of 'sufficiently close to zero'. }\end{array}$ & It is best for him to be the first mover & $\begin{array}{c}\text { Theoretical proof } \\
\text { Observation } 7\end{array}$ \\
\hline 11 & $\begin{array}{l}\text { How does a player's } \\
\text { discount factor effect } \\
\text { his shares? }\end{array}$ & $\begin{array}{l}\text { For single cycle bargaining games, } \\
\text { the first mover's share does not depend } \\
\text { on his discount factor. The share of each } \\
\text { veto player who is not the first mover } \\
\text { is increasing in his discount factor }\end{array}$ & $\begin{array}{c}\text { Theoretical proof } \\
\text { Theorems } 11 \text { and } 16\end{array}$ \\
\hline
\end{tabular}

Table 1 A summary of the key research questions and results. The results in blue are only for the zero conflict point, those in red are only for a non-zero conflict point, and those in black are for both cases. $A_{1}$ denotes the first mover for the bargaining and $Z$ the set of (Bayesian) veto players. 
To this end, we propose a bargaining game that runs over a series of rounds. The agents take it in turns to propose a division of the pie: the order in which players make proposals is defined by an exogenous agenda. After a proposal is made, the remaining players vote on whether to accept or reject it. Voting takes place using a weighted voting game, in which each player has a weight, and a proposal is accepted if the sum of the weights of those in favour of the proposal meets or exceeds a certain quota. If a proposal is accepted, then it is implemented; otherwise we turn to the next player on the agenda to make a proposal in the next round. If no proposal is accepted by a fixed deadline, i.e., there is a conflict, all the players receive nothing.

The proposed bargaining game is useful for modeling a number of multi-agent situations. For example, consider, the International Olympic Committee selecting a host for Olympic games. Different countries submit bids. Within a country, a set $A$ of parties may be interested in collaborating on a bid but a subset $C \subseteq A$ must be chosen to form a bid. For instance, a bid could involve a coalition of players such as New York City, New York State, the U. S. Federal Government, and some representatives of the private sector. The relative importance of an individual player is given by a weight. Those coalitions whose cumulative weight meets or exceeds a quota are able to generate the pie (i.e., have enough resources to bid). One such coalition must form and the players must decide how to divide the pie between themselves.

In the above example, the relative importance of a player may not be known at the time of bidding since the bidding happens much in advance of the actual events. As a result, the players will be uncertain with regard to their weights, i.e., they have imperfect information about their weights. We model imperfect information with a Bayesian voting game [22].

The key results of our research are as follows. For our bargaining game, we provide a Bayesian subgame perfect equilibrium (SPE) and conduct an ex-ante analysis of the resulting outcome. We show that the equilibrium is unique, is computable in polynomial time, results in an instant Pareto optimal agreement, and, under certain conditions (given in Section 4) provides a foundation for the core and the nucleolus of the Bayesian voting game. In addition, our analysis generates the following key insights about the noncooperative equilibrium: i) a player's share is independent of his weight and depends only on whether he is a veto player or not, ii) every non-veto player who is not the first mover will get nothing regardless of the agenda, iii) every veto player will get a non-zero share that depends on his position on the agenda, iv) if there are no veto players, then the first mover will get the entire pie regardless of how the remaining players are arranged on the agenda. Finally, we show that changing the conflict point from one where all the players receive nothing to one where each player receives a constant share makes the problem of computing the noncooperative equilibrium NP-hard even under the perfect information assumption. Our research also reveals how this change in conflict point impacts on the relation between the non-cooperative equilibrium and the ex-ante core/nucleolus of the Bayesian voting game.

Table 1 provides a more detailed summary of the main research questions addressed in the paper and the key results obtained. The paper makes two key contributions i) we address some established research questions - how to obtain a noncooperative equilibrium, what are its properties, and how it links to the core - in a new 


\begin{tabular}{|c|c|}
\hline$p \in \mathbb{N}$ & The number of players \\
\hline$x \in[0,1]^{p}$ & The allocation vector \\
\hline$u_{i}:[0,1] \times \mathbb{N} \rightarrow \mathbb{R}_{+}$ & Player $i$ 's utility function \\
\hline$\delta_{i} \in(0,1]$ & Player $i$ 's discount factor \\
\hline$W \in \mathbb{R}_{+}^{p}$ & The weight vector \\
\hline$q \in \mathbb{R}_{+}$ & The quota for the weighted voting game \\
\hline$A=\{1, \ldots, p\}$ & A set of $p$ players \\
\hline$G=\langle A, W, q\rangle$ & A weighted voting game \\
\hline$C \subseteq A$ & A coalition of the players in $A$ \\
\hline$v: 2^{P} \rightarrow\{0,1\}$ & The value function for the weighted voting game \\
\hline$Z \subset A$ & The set of veto players in $A$ \\
\hline $0 \leq z<p$ & The number of veto players in $A$ \\
\hline$N \subseteq A$ & The set of non-veto players in $A$ \\
\hline $0<n \leq p$ & The number of non-veto players in $A$ \\
\hline$S_{w}$ & The set of all winning coalitions \\
\hline$S_{l}$ & The set of all losing coalitions \\
\hline$m \in \mathbb{N}$ & The number of bargaining cycles \\
\hline$T=m \cdot p$ & The bargaining deadline \\
\hline $\mathbb{O} \in[0,1]^{p}$ & The conflict point \\
\hline$b$ & The number of possible weight vectors \\
\hline$B \in[0,1]^{b}$ & A probability distribution over the weight vectors \\
\hline$G=\langle A, W, B, q\rangle$ & A Bayesian weighted voting game \\
\hline$B G=\langle A, W, B, q, \mathbb{O}, T, \delta\rangle$ & A non-cooperative bargaining game \\
\hline$Z_{i}$ & The position of the $i$ th veto player on the agenda \\
\hline$\delta_{L}$ & The discount factor for the last veto player on the agenda \\
\hline$C_{a c c}^{t} \subseteq A$ & The set of players that accept the proposal made at time $t$ \\
\hline$C_{r e j}^{t} \subseteq A$ & The set of players that reject the proposal made at time $t$ \\
\hline$N_{+}^{t} \subseteq N$ & The set of (Bayesian) non-veto players who get a positive share in the equilibrium for time $t$ \\
\hline $0 \leq n_{+}^{t} \leq n$ & The number of (Bayesian) non-veto players who get a positive share in the equilibrium for time $t$ \\
\hline$N_{0}^{t} \subseteq N$ & The set of (Bayesian) non-veto players who get nothing in the equilibrium for time $t$ \\
\hline $0 \leq n_{0}^{t} \leq n$ & The number of (Bayesian) non-veto players who get nothing in the equilibrium for time $t$ \\
\hline$x_{a}^{i, j}$ & Player $a$ 's equilibrium share for the $i$ th time period of cycle $j$ \\
\hline
\end{tabular}

Table 2 A summary of notation.

and more realistic bargaining context, and ii) we address new research questions how the non-cooperative equilibrium links to the nucleolus, how a player's position on the agenda affects his equilibrium share, how the conflict point impacts on the complexity of computing the non-cooperative equilibrium, and how it impacts on the relation between the non-cooperative equilibrium and the core/nucleolus - in the new context.

Section 2 introduces our bargaining game. In Section 3, we analyze its equilibrium. The relation between the non-cooperative equilibrium and the core (nucleolus) is shown in Section 4 (Section 5). The relation between a player's position on the agenda and his equilibrium share of the pies explored in Section 6. Section 7 shows how changing to a non-zero conflict point impacts on the complexity of computing the non-cooerative equilibrium, and also how it impacts on the relation between the non-cooperative equilibrium and the core/nucleolus. Section 8 discusses related literature and Section 9 concludes. Our notation is summarized in Table 2. 


\section{The Model}

There is a set $A=\{1, \ldots, p\}$ of agents and a resource modeled as a unit-sized divisible pie. The pie can be generated by the entire set $A$ but also by some of its subsets. Given these subsets, we must decide how to allocate the pie to the agents in $A$. An allocation specifies how the pie is split between the players, and is represented as a vector $\left(x_{1}, \ldots, x_{p}\right)$. The element $x_{i}\left(0 \leq x_{i} \leq 1\right)$ denotes player $i$ 's allocation, i.e., the amount of the resource that player $i$ receives. The total allocation must be $\sum_{i} x_{i} \leq 1$. A player's utility from an allocation depends both on his share of the pie and the time at which he receives his allocation. Time is divided into discrete time periods numbered $1,2, \ldots$. Player $i$ 's utility from an allocation $x$ at time $t$ is defined as:

$$
u_{i}(x, t)=\delta_{i}^{t-1} \cdot x_{i}
$$

where $0<\delta_{i} \leq 1$ is $i$ 's discount factor. Thus, the discount factors are heterogeneous, and, at time $t, i$ 's utility gets discounted by $\delta_{i}^{t-1}$.

The $p$ players want to implement an allocation that has majority support. For this, we propose a non-cooperative bargaining game. This is a finite-horizon game of $T$ discrete time periods, i.e., bargaining must end within $T$ rounds. In each round, a chosen player makes an offer that specifies an allocation. The outcome of bargaining is an offer that has majority support. Majority support is modelled with a weighted voting game.

\subsection{The Weighted Voting Game $G$}

A weighted voting game (WVG) is a triple $G=\langle A, W, q\rangle$ where $A=\{1, \ldots, p\}$ is the set of players, $w$ is the weight vector with $W_{i}>0$ denoting the weight for player $1 \leq i \leq p$, and $q \in \mathbb{R}$ is the quota. A coalition $C$ is a subset of $A$, i.e., $C \subseteq A$ (although sometimes, for ease of discussion, we will denote a coalition as a binary string $\zeta \in\{0,1\}^{p}$ ). The total weight of coalition $C \subseteq A$ is $W(C)=\sum_{i \in C} W_{i}$. The characteristic function $v: 2^{A} \rightarrow\{0,1\}$ of a game $G$ is:

$$
v(C)= \begin{cases}1 & \text { if } \sum_{i \in C} W_{i} \geq q \\ 0 & \text { otherwise }\end{cases}
$$

A coalition $C \subseteq A$ is winning if $v(C)=1$, otherwise it is losing. The interpretation is that any winning coalition is able to generate the pie.

A player is called a veto player if a winning coalition cannot be formed without him, i.e., $i$ is a veto player if for each $C \subseteq N$ such that $v(C)=1$, we have $i \in C$. Let $Z \subset A$ denote the set of all veto players with $|Z|=z$, and $N \subseteq A$ the set of all non-veto players with $|N|=n$. Also, let $S_{w}\left(S_{l}\right)$ be the set of all winning (losing) coalitions. 


\subsection{The Noncooperative Bargaining Game}

The proposed bargaining game $(B G)$ proceeds in a series of rounds. We let the bargaining deadline be $T=m \cdot p$ for a finite integer $m \geq 1$, i.e., an agreement must be reached within $T$ rounds, otherwise all the players will get a conflict share of zero ${ }^{2}$. Such an exogenous setting of deadline can happen in real world situations. Consider, the example of the International Olympic Committee selecting a host for the Olympic games. Different countries submit bids. A bid involves a coalition of interested parties such as New York City, New York State, the U. S. Federal Government, and some representatives of the private sector. Such a coalition must be a winning coalition in that its members must together have all resources needed to make a bid. Between all the parties interested in joining a bid, a winning coalition must form. Note that, there may be more than one possible winning coalition. The members of the winning coalition must also decide how they will split the gains of cooperation (i.e., the pie) between themselves. The proposed bargaining game is a means of forming a winning coalition and deciding upon a division of the pie. Here, the bargaining deadline is set by the International Olympic Committee, not by the bargainers.

By letting $T$ be a multiple of $p$, we give all the players an equal number of chances to make a proposal. Note that, $m$ could be any positive integer and this is what we mean by flexible deadline. Let the agenda be defined exogenously. Without loss of generality, suppose that player $i$ is the $i$ th player on the agenda. Thus, unless stated otherwise, the agenda will be $(1, \ldots, p)$.

Bargaining begins at $t=1$ with player 1 proposing an offer $x^{t}=\left(x_{1}^{t}, \ldots, x_{p}^{t}\right)$ (with $\sum_{i=1}^{p} x_{i}^{t} \leq 1$ ) that specifies how to split the pie between the $p$ players. All the remaining players then respond by either accepting or rejecting $x^{t}$. Let $C_{a c c}^{t}$ denote the set of players that accept the proposal $x^{t}$ and $C_{\text {rej }}^{t}$ those that reject it. If $\sum_{i \in C_{a c c}^{t}} W_{i} \geq q$, the game ends at $t$ and the pie is split as per the offer $x^{t}$. But, if $\sum_{i \in C^{t}} W_{i}<q$, time is incremented and bargaining proceeds to the second round when player 2 will propose. The remaining players $1,3, \ldots, p$ respond. If player 2 gets majority support, then the pie is split as per $x^{2}$ (i.e., player 2's offer) and the game ends. Otherwise, the process repeats. If no winning coalition is formed within $T$ time periods, the game ends and all the players get a conflict share of zero. Let $\mathbb{O}=\mathbf{0}$ denote this conflict point, where $\mathbf{0}$ denotes a vector of $p$ zeros.

Note that, as $T=m \cdot p$, the order in which the players are called to make a proposal is $1, \ldots, p, 1, \ldots, p, \ldots$ Thus, for a time $t=(m-X-1) \cdot p+i$ (where $0 \leq X \leq m-1$ and $1 \leq i \leq p$ ), player $i$ will be the proposer. We will call the time periods 1 to $p$ the first bargaining cycle. Thus, cycle $1 \leq i \leq m$ comprises time periods $(i-1) \cdot p+1 \ldots, i \cdot p$.

Formally, the bargaining game is defined as the tuple $B G=\langle A, w, q, \mathbb{O}, T, \delta\rangle$. The positions of the veto players on the agenda $A$ will be denoted as follows. We will let $Z_{i} \in P$ denote the position of the $i$ th veto player on the agenda. Let the first veto player be positioned at distance $d_{0}^{1} \geq 0$ from the first mover, i.e., the first veto player is at position $1+d_{0}^{1}$ on the agenda. The second veto player is at distance $d_{1}^{2} \geq 1$ from the first veto player, i.e., the second veto player is at position $1+d_{0}^{1}+d_{1}^{2}$ on the

\footnotetext{
2 In Section 7, we will consider non-zero conflict shares.
} 


\begin{tabular}{|l|l|}
\hline Player & Position on the agenda \\
\hline 1 st mover & 1 \\
\hline$\vdots$ & $\vdots$ \\
\hline 1 st veto player & $Z_{1}=1+d_{0}^{1}$ \\
\hline$\vdots$ & $\vdots$ \\
\hline 2 nd veto player & $Z_{2}=1+d_{0}^{1}+d_{1}^{2}$ \\
\hline$\vdots$ & $\vdots$ \\
\hline$i$ th veto player & $Z_{i}=1+d_{0}^{1}+d_{1}^{2}+\ldots+d_{i-1}^{2}$ \\
\hline$\vdots$ & $\vdots$ \\
\hline$z$ th veto player & $Z_{z}=1+d_{0}^{1}+d_{1}^{2}+\ldots+d_{z-1}^{z}$ \\
\hline$\vdots$ & $\vdots$ \\
\hline Last mover & $1+d_{0}^{1}+d_{1}^{2}+\ldots+d_{z-1}^{z}+d_{z}^{p}=p$ \\
\hline
\end{tabular}

Table 3 Each veto player's on the agenda.

agenda. In general, the $i$ th veto player will be at distance $d_{i-1}^{i} \geq 1$ from the $(i-1)$ th veto player, i.e., the $i$ th veto player is at position $1+d_{0}^{1}+d_{1}^{2}+\ldots+d_{i-1}^{i}$ on the agenda. The last mover is at distance $d_{z}^{p} \geq 0$ from the $z$ th veto player (i.e., the last mover is at position $1+d_{0}^{1}+d_{1}^{2}+\ldots+d_{z-1}^{z}+d_{z}^{p}=p$ ) on the agenda. Table 3 shows the positions of the veto players on the agenda.

\section{Noncooperative Equilibrium Analysis}

We first show how to obtain equilibrium for the perfect information setting and then for an imperfect information setting.

\subsection{The Perfect Information Setting}

We will show how to obtain equilibrium strategies using backward induction first in the context of Example 1 and then, in Theorem 1, we will characterize the equilibrium for any general bargaining situation.

Example 1 There are three bargainers $A=\{1,2,3\}$ with weights $W=(2,1,2)$. The quota is $q=4$, the deadline is $T=6$, and the agenda is $(1,2,3)$.

The veto players are $Z=\{1,3\}$. Since the agenda is $(1,2,3)$, player 1 will propose in rounds 1 and 4, player 2 in rounds 2 and 5, and player 3 in rounds 3 and 6 . Consider the last round $t=6$ when player 3 will propose. Since this is the last round, player 3 will keep the entire pie by offering $x^{6}=(0,0,1)$, and the others will accept. In the previous round $t=5$, player 2 will give to player 3 his discounted share (i.e., $x_{3}^{5}=\delta_{3}$ ) since player 3 is a veto player, nothing to player 1 since his discounted share is zero, and keep the remaining pie (i.e., $x_{2}^{5}=1-\delta_{3}$ ) for himself. Then, at $t=4$, player 1 will give $x_{3}^{4}=\left(\delta_{3}\right)^{2}$ to player 3 (since he is a veto player), nothing to 


\begin{tabular}{|c|l|}
\hline Time $(t)$ & Equilibrium strategy \\
\hline$t=(m-X-1) \cdot p+i$ & Player $i$ : Find a $\zeta$ that solves $O_{t}:$ \\
& $O_{t}:$ Minimize $\sum_{j \in A \backslash\{i\}} x_{j}^{t+1} \cdot \delta_{j} \cdot \zeta_{j}$ \\
$0 \leq X \leq m-1$ & s.t. $\sum_{j \in A \backslash\{i\}} W_{j} \cdot \zeta_{j}+W_{i} \geq q$ \\
& $\zeta_{j} \in\{0,1\}$ for $j \in A \backslash\{i\} ; \zeta_{i}=1$ \\
$1 \leq i \leq p$ & $\begin{array}{c}\text { Propose } x^{t} \text { where } \\
x_{j}^{t}=\delta_{j} \cdot x_{j}^{t+1} \cdot \zeta_{j} \text { for } j \neq i\end{array}$ \\
& $x_{i}^{t}=1-\sum_{j \in A \backslash\{i\}} x_{j}^{t}$ \\
& \\
Proposer: player $i$ & Each player $j \in A \backslash\{i\}$ responds to $x^{t}:$ \\
& If $u_{j}\left(x^{t}, t\right) \geq u_{j}\left(x^{t+1}, t+1\right)$ Accept \\
& Else Reject \\
\hline$t=T$ & Player $p$ proposes to keep the whole pie \\
Proposer: player $p$ & and all the other players accept. \\
\hline
\end{tabular}

Table 4 Subgame perfect equilibrium strategies.

player 2 (since he is a non-veto player), and keep $x_{1}^{4}=1-\left(\delta_{3}\right)^{2}$ for himself. Thus, player 1 will form a winning coalition with player 3 . Then at $t=3$, player 3 will give $x_{1}^{3}=\left(1-\left(\delta_{3}\right)^{2}\right) \cdot \delta_{1}$ to player 1 , nothing to player 2 , and keep $x_{3}^{3}=\left(1-\delta_{1}+\left(\delta_{3}\right)^{2} \cdot \delta_{1}\right)$ for himself. Continuing in the same way, we can see that an agreement will occur at $t=1$ and result in the shares $\left(1-\left(\delta_{3}\right)^{2}+\delta_{1} \cdot\left(\delta_{3}\right)^{2}-\delta_{1} \cdot \delta_{3}^{4}, 0,\left(\delta_{3}\right)^{2}-\delta_{1} \cdot\left(\delta_{3}\right)^{2}+\delta_{1} \cdot \delta_{3}^{4}\right)$.

In Example 1, only the veto players 1 and 3 get a non-zero share while the nonveto player gets nothing. However, depending on the agenda, it is possible for the nonveto player to also get a positive share in the pie. This is illustrated in the following example

Example 2 There are three bargainers $A=\{1,2,3\}$ with weights $W=(2,1,2)$. The quota is $q=4$, the deadline is $T=3$, the discount factors are $\delta_{1}=1 / 3$, $\delta_{2}=1 / 4$, and $\delta_{3}=1 / 5$. The agenda is $(2,1,3)$.

We begin with the last time period $t=3$ when player 3 will propose the offer $x^{3}=$ $(0,0,1)$. Player 3's utility from it will be $\left(\delta_{3}\right)^{2}=1 / 25$. In the previous time period $t=2$, player 1 will propose $x^{2}=(0,4 / 5,1 / 5)$. Player 3's utility from it will be $1 / 5 \times \delta_{3}=1 / 25$ and that of player 1 will be $4 / 5 \times \delta_{1}=4 / 15$. Given this, the first mover, i.e., the non-veto player will propose $x^{1}=(52 / 75,4 / 15,1 / 25)$ and the two veto players will immediately agree.

We are now ready to characterise equilibrium strategies. These strategies are obtained by backward induction (backward induction is also used to obtain equilibrium for bilateral bargaining $[36,30]$ with deadlines). In the following text, $x_{i}^{t}$ will denote player $i$ 's equilibrium share for time $t$.

Theorem 1 A bargaining game $B G=\langle A, W, q, \boldsymbol{0}, T, \delta\rangle$ with $0 \leq z<p$ veto players, admits the subgame perfect equilibrium given in Tables 4 and 5 , and results in an immediate agreement.

Proof We use backward induction. For the last time period $t=m p$, the player $p$ will propose to keep a hundred percent of the pie and all the remaining players will agree. Thus, the equilibrium shares will be $x=(0, \ldots, 0,1)$ (see the last row in Table 5). 


\begin{tabular}{|c|c|}
\hline Time period $(t)$ & Equilibrium shares $(x)$ \\
\hline $\begin{array}{c}t=1 \\
\text { Proposer: player } 1\end{array}$ & $\begin{array}{l}\left(\mathbf{x}_{1}^{1}, \ldots, \mathbf{x}_{\mathbf{p}}^{1}\right) \text { where } \\
x_{j}^{1}=0 \quad \text { if }(j>1 \text { and } j \notin Z) \\
x_{j}^{1}=x_{j}^{2} \cdot \delta_{j} \quad \text { if } j \in Z \backslash\{1\} \\
x_{1}^{1}=1-\sum_{j \in Z \backslash\{1\}} x_{j}^{1}\end{array}$ \\
\hline$\cdots$ & $\cdots$ \\
\hline $\begin{array}{c}t=(m-X-1) \cdot p+i \\
0 \leq X \leq m-1 \\
\quad 1 \leq i \leq p \\
\text { Proposer: player } i\end{array}$ & $\begin{array}{l}\left(\mathbf{x}_{\mathbf{1}}^{\mathbf{t}}, \ldots, \mathbf{x}_{\mathbf{p}}^{\mathbf{t}}\right) \text { where } \\
x_{j}^{t}=0 \quad \text { if }(j \neq i \text { and } j \notin Z) \\
x_{j}^{t}=x_{j}^{t+1} \cdot \delta_{j} \quad \text { if } j \in Z \backslash\{i\} \\
x_{i}^{t}=1-\sum_{j \in Z \backslash\{i\}} x_{j}^{t}\end{array}$ \\
\hline$\cdots$ & $\cdots$ \\
\hline $\begin{array}{c}t=(m-1) \cdot p+1 \\
\text { Proposer: player } 1\end{array}$ & $\begin{array}{l}\left(\mathbf{x}_{1}^{\mathbf{t}}, \ldots, \mathbf{x}_{\mathbf{p}}^{\mathbf{t}}\right) \text { where } \\
x_{j}^{t}=0 \quad \text { if }(j>1 \text { and } j \notin Z) \\
x_{j}^{t}=x_{j}^{t+1} \cdot \delta_{j} \quad \text { if } j \in Z \backslash\{1\} \\
x_{1}^{t}=1-\sum_{j \in Z \backslash\{1\}} x_{j}^{t}\end{array}$ \\
\hline$\cdots$ & $\cdots$ \\
\hline $\begin{array}{c}t=(m-1) \cdot p+i \\
1 \leq i \leq p \\
\text { Proposer: player } i\end{array}$ & $\begin{array}{l}\left(\mathbf{0}, \ldots, \mathbf{0}, \mathbf{x}_{\mathbf{i}}^{\mathbf{t}}, \ldots, \mathbf{x}_{\mathbf{p}}^{\mathbf{t}}\right) \text { where } \\
x_{j}^{t}=0 \text { if }(j<i) \text { or }(j>i \text { and } j \notin Z) \\
x_{j}^{t}=x_{j}^{t+1} \cdot \delta_{j} \text { if } j \in Z \cap\{i+1, \ldots, p\} \\
x_{i}^{t}=1-\sum_{j \in Z \backslash\{i\}} x_{j}^{t}\end{array}$ \\
\hline$\cdots$ & $\cdots$ \\
\hline $\begin{array}{c}t=m \cdot p-1 \\
\text { Proposer: player } p-1\end{array}$ & $\begin{array}{l}\left(\mathbf{0}, \ldots, \mathbf{0}, \mathbf{x}_{\mathbf{p}-\mathbf{1}}^{\mathbf{t}}, \mathbf{x}_{\mathbf{p}}^{\mathbf{t}}\right) \text { where } \\
x_{p-1}^{t}=1 \text { and } x_{p}^{t}=0 \text { if } p \notin Z \\
x_{p-1}^{t}=1-\delta_{p} \text { and } x_{p}^{t}=\delta_{p} \text { if } p \in Z\end{array}$ \\
\hline $\begin{array}{c}t=m \cdot p \\
\text { Proposer: player } p\end{array}$ & $(\mathbf{0}, . ., \mathbf{0}, \mathbf{1})$ \\
\hline
\end{tabular}

Table 5 Equilibrium shares for the game $B$.

In each of the previous time periods $t<T$, the proposer (say player $i$ ) will consider the set of all possible winning coalitions containing $i$. For each such coalition $C \subseteq A$, the optimal offer will maximize $i$ 's share $x_{i}^{t}=1-\sum_{j \in C \backslash\{i\}} \delta_{j} \cdot x_{j}^{t+1}$ while giving to each player in $C \backslash\{i\}$ his discounted share for $t+1$, and nothing to those players that do not belong to $C \backslash\{i\}$. Between all these optimal offers, the one that maximizes $x_{i}^{t}$ (or, equivalently, minimizes $\sum_{j \in C \backslash\{i\}} \delta_{j} x_{j}^{t+1}$ ) will be his equilibrium offer. Then, we must find $a \zeta \in\{0,1\}^{p}$ that solves $O_{t}$ (see Table 4).

Consider $t=m \cdot p-1$ when player $p-1$ will propose. His offer will depend on whether the last mover, i.e., player $p$, is a veto player or not. If $p \in Z$, then the proposer $p-1$ needs player $p$ to form a winning coalition and must give to $p$ his discounted share for the next time period, i.e., $x_{p}^{t}=\delta_{p}$. But the proposer will give nothing to the players $1, \ldots, p-2$, i.e., $x_{j}^{t}=0$ for $1 \leq j \leq p-2$. Thus, $p-1$ will keep $x_{p-1}^{t}=1-\delta_{p}$ for himself. Here, the winning coalition will be $A$. But if $p \notin Z$, $p-1$ can form a winning coalition with some or all of the players in $\{1, \ldots, p-2\}$. Since all the players in $\{1, \ldots, p-2\}$ get nothing in the equilibrium for $T, p-1$ will propose to keep the whole pie and all the players in $\{1, \ldots, p-2\}$ will accept. Thus, the winning coalition will be $A \backslash\{p\}$, and the equilibrium shares will be as given in row $(m \cdot p-1)$ of Table 5. Note that, $p-1$ will get a non-zero share regardless of whether he is a veto player or not, and the last mover will get a non-zero share only if 
he is a veto player. Thus, only the players in $\{p-1\} \cup(Z \cap\{p\})$ will get a non-zero share while the rest get nothing.

Backward induction for rows of Table 5 marked in red lines: Consider $t=(m-$ $1) \cdot p+i$ (for $1 \leq i \leq p-1$ ) when mover $i$ will propose. We will assume that the equilibrium shares are $\left(0, \ldots, 0, x_{i}^{t}, \ldots, x_{p}^{t}\right)$ where $x_{j}^{t}=0$ if $(j<i)$ or $(j>i$ and $j \notin Z), x_{j}^{t}=x_{j}^{t+1} \cdot \delta_{j}$ if $j \in Z \cap\{i+1, \ldots, p\}$, and $x_{i}^{t}=1-\sum_{j \in Z \backslash\{i\}} x_{j}^{t}$. In words, we will assume that only the players in $Z \cap\{i+1, \ldots, p\} \cup\{i\}$ get a non-zero share while the rest get nothing at $t$. Given this assumption, we will prove that the equilibrium shares for $t-1$ will be $\left(0, \ldots, 0, x_{i-1}^{t-1}, \ldots, x_{p}^{t-1}\right)$ where $x_{j}^{t-1}=0$ if $(j<i-1)$ or $(j>i-1$ and $j \notin Z), x_{j}^{t-1}=x_{j}^{t} \cdot \delta_{j}$ if $\left.j \in Z \cap\{i, \ldots, p\}\right)$, and $x_{i}^{t-1}=1-\sum_{j \in Z \backslash\{i\}} x_{j}^{t-1}$. I.e., we will prove that only player $i-1$ and the veto players in $\{i, \ldots, p\}$ will get a non-zero share while the rest get nothing at $t-1$.

Consider the time $t-1$ when $i-1$ 's offer will be a solution to $O_{t-1}$. The proposer will be able to form a winning coalition with all the veto players and some non-veto players. We are given that, at $t$, only player $i$ and the veto players in $\{i+1, \ldots, p\}$ get a non-zero share while the rest get nothing. This implies that, player $i-1$ must give each veto player in $\{i+1, \ldots, p\}$ his discounted share for the next time period. If player $i$ is a non veto, then $i-1$ will be able to get majority support without $i$ 's vote. In other words, $i-1$ will offer nothing to $i$. Therefore, at $t-1$, only the players $i-1$ and the veto players in $\{i, \ldots, p\}$ will get a non-zero share and the rest get nothing. Here, the winning coalition will be $A$ if $i \in Z$, and $A \backslash\{i\}$ otherwise.

Backward induction for rows of Table 5 marked in black lines: Going further back, consider a time $t=(m-X-1) \cdot p+i$ for some $0 \leq X \leq m-1$ and some $1 \leq i \leq p$ when player $i$ will be the proposer. We will assume that the equilibrium shares are $\left(x_{1}^{t}, \ldots, x_{p}^{t}\right)$ where $x_{j}^{t}=0$ if $(j \neq i$ and $j \notin Z), x_{j}^{t}=x_{j}^{t+1} \cdot \delta_{j}$ if $j \in Z \backslash\{i\}$, and $x_{i}^{t}=1-\sum_{j \in Z \backslash\{i\}} x_{j}^{t}$. In words, we will assume that only the players in $Z \cup\{i\}$ get a non-zero share while the rest get nothing at $t$. Given this assumption, we will prove that the equilibrium shares for $t-1$ will be $\left(x_{1}^{t-1}, \ldots, x_{p}^{t-1}\right)$ where $x_{j}^{t-1}=0$ if $(j \neq$ $i-1$ and $j \notin Z), x_{j}^{t-1}=x_{j}^{t} \cdot \delta_{j}$ if $j \in Z \backslash\{i-1\}$, and $x_{i}^{t-1}=1-\sum_{j \in Z \backslash\{i-1\}} x_{j}^{t-1}$. That is, we will prove that only the players in $\{i-1\} \cup Z$ will get a non-zero share while the rest get nothing at $t-1$.

Consider the time period $t-1$ when $i-1$ will propose an offer that solves $O_{t-1}$ defined in Table 4. We know that, the proposer will be able to form a winning coalition with all the veto players and some non-veto players. In addition, we are given that, at $t$, only the players in $Z \cup\{i\}$ get a non-zero share while the rest get nothing. This implies that, the proposing player $(i-1)$ must give each veto player his discounted share for the next time period and form a winning coalition without $i$ if $i$ is non veto. Thus, if $i$ is non veto, he will get no share in the pie. This means that, at $t-1$, only the players in $\{i-1\} \cup Z$ will get a non-zero share and the rest get nothing. The winning coalition will be $A$ if $i \in Z$, and $A \backslash\{i\}$ otherwise.

Thus, we get the equilibrium shares as given in Table 5. An agreement will result in the first time period. 
Theorem 1 has the following interesting corollaries.

Observation 1 A player's equilibrium share depends not on his weight but on whether he is a veto player or not. For the agenda $(1, \ldots, p)$, the first mover (regardless of whether he is a veto player or not) will get a non-zero share in the pie. Every veto player will get a non-zero share. None of the non-veto players in $\{2, \ldots, p\}$ will get any share (indeed, this is what we saw in Example 1: player 2, the only non-veto player, got nothing and the pie was split between the two veto players). If there are no veto players (i.e., $z=0$ ), then the first mover will get the entire pie and the rest will get nothing.

Observation 2 The equilibrium outcome is unique: for each time period, we have a unique utility maximizing allocation. It is individual rational (IR) since each player gets a non-negative share in the pie. It is also Pareto optimal (PO) since, in the equilibrium for each time period, the pie is fully allocated to some non-empty subset of players in A. In addition, there is instant agreement so the pie is not wasted through shrinkage (there would be wastage from shrinkage if an agreement were to result at $t>1)$.

Theorem 2 The equilibrium shares for the first time period can be computed in time $\mathcal{O}(m \cdot p)$.

Proof If $\left(\sum_{j \in A} W_{j}\right)-W_{i}<q$ then player $i \in A$ is a veto player. It takes $\mathcal{O}(p)$ time to determine if $i$ is a veto player or not. Which of the p players are veto can be determined in $\mathcal{O}(p)$ time. The equilibrium shares for the last time period $t=T$ are $(0, \ldots, 0,1)$. For each time period $t<T$, each player's discounted share can be computed in constant time. In the equilibrium for $t$, each veto player will get his discounted share. In addition, the equilibrium allocation for each time period is unique. Since there are $p$ players, the total time to compute the equilibrium shares for $t$ will be $\mathcal{O}(p)$. There are $T=m p$ time periods in all, and we go backward from the last to the first time period. Thus, the equilibrium shares for the first time period can be computed in $\mathcal{O}(m p)$ time.

\subsection{An Imperfect Information Setting}

We now consider uncertainty over the players' weights in the WVG. In a multi-agent setting, a player's weight could represent the quality or quantity of resources it possesses. Recall the example of selecting a host for Olympic games. Here, the weight of a player depends on his relative importance or the number of individuals he represents. Since the bidding happens much earlier than the actual event, it is unlikely that the parties will know the actual weights at the time of placing a bid. But later, all the bargainers will know all the weights. At this time, it will be a game of perfect information. In examples such as this, the players would be uncertain with regard to their weights and we model this uncertainty with the following Bayesian WVG of imperfect information. This Bayesian WVG belongs to the class of Bayesian coalitional games defined in [22]. 
In the Bayesian voting game, there are $b$ possible weight vectors and $W_{i}^{j}$ denotes the weight of player $i$ in the $j$ th vector. The players have probabilistic beliefs over these vectors; $B^{j}$ denotes the probability that the weight vector is $W^{j}$ and $\sum_{j}^{b} B^{j}=$ 1 . For $b=1$, this setting reduces to the perfect information setting. Thus, a Bayesian WVG is defined as the 4-tuple $G=(A, W, B, q)$. We assume that $W, B, q, T, \delta$, and the agenda are known to all the players.

For this setting, the bargaining game is $B G=\langle A, W, B, q, \mathbb{O}, T, \delta\rangle$. There are three distinct time frames at which a game of imperfect information can be analysed: the ex-ante stage, the interim stage, and the ex-post stage [16]. We conduct equilibrium analysis at the ex-ante stage, i.e., when no agent knows his weight. This is an average-case analysis i.e., it gives an indication of the players' expected shares based on the probability distribution for the weights. It is particularly useful in situations (such as the example given above) where the weights are given by a probability distribution. The players initially know only the probability distributions for the weights but will know the actual weights before playing the game, i.e., they have perfect information before playing the game.

We define the Bayesian weight of a coalition $C \subseteq A$ as $\bar{W}(C)=\sum_{j=1}^{b} B^{j}$. $\left(\sum_{i \in C} W_{i}^{j}\right)$. In words, $\bar{W}(C)$ is the expected weight of coalition $C$. Player $i$ is a Bayesian veto player if $\sum_{j=1}^{b} B^{j} \cdot\left(\sum_{k \in A \backslash\{i\}} W_{k}^{j}\right)<q$, otherwise, he is not. In words, player $i$ is a Bayesian veto player if the expected weight of the coalition $A \backslash\{i\}$ is lower than the quota (i.e., $A \backslash\{i\}$ is a losing coalition), otherwise $i$ is Bayesian nonveto player. For this setting, let the $z=|Z|$ element set $Z$ denote the set of Bayesian veto players. The characteristic function for $G=(A, w, B, q)$ is defined as:

$$
\bar{v}(C)= \begin{cases}1 & \text { if } \quad \bar{W}(C) \geq q \\ 0 & \text { otherwise }\end{cases}
$$

Thus, a coalition is ex-ante winning if its expected weight equals or exceeds the quota. Otherwise, it is losing. In what follows, the set $S_{w}\left(S_{l}\right)$ will denote the set of all ex-ante winning (losing) coalitions. Before characterizing the equilibrium for this imperfect information setting, we will work out the equilibrium for Example 3.

Example 3 There are three players $A=\{1,2,3\}$. There are $b=2$ weight vectors: $W^{1}=(1,2,3)$ with probability $1 / 3$ and $W^{2}=(2,1,2)$ with probability $2 / 3$. The quota is $q=4$. The deadline is $T=6$. The discount factors are $\delta_{1}=1 / 4, \delta_{2}=1 / 2$, and $\delta_{3}=3 / 4$. The agenda is $(1,2,3)$.

Here, the set of Bayesian veto players is $Z=\{1,3\}$ since $\bar{W}(1,2)<q, \bar{W}(1,3)=$ $q$ and $\bar{W}(2,3)<q$. Given $Z$, we can find the equilibrium for $B$ using backward induction in just the same way as we did for the perfect information setting. In the last round $t=6$, the proposer, i.e., player 3, will keep the entire pie and the other two players get nothing. In the previous round $t=5$, the proposer, i.e., player 2 , will form a winning coalition by giving $\delta_{3}$ to player 3 (since he is a Bayesian veto player who gets positive utility in the last time period), nothing to player 1 (since he is a Bayesian veto player but he gets nothing in the last time period), and keeping $1-\delta_{3}$ for himself. So the shares will be $\left(0,\left(1-\delta_{3}\right) \cdot \delta_{2}^{4}, \delta_{3}^{5}\right)$. Continuing backward, we get $\left(1-\left(\delta_{3}\right)^{2}+\delta_{1} \cdot\left(\delta_{3}\right)^{2}-\delta_{1} \cdot \delta_{3}^{4}, 0,\left(\delta_{3}\right)^{2}-\delta_{1} \cdot\left(\delta_{3}\right)^{2}+\delta_{1} \cdot \delta_{3}^{4}\right)$ as the shares for $t=1$. 
Here, both Bayesian veto players get a non-zero share and the non-veto player gets nothing. By changing the agenda to $A=(2,1,3)$, one can verify that all the three players will get a non-zero share at $t=1$.

We are now ready to characterize the equilibrium.

Theorem 3 A bargaining game $B G=\langle A, W, B, q, \boldsymbol{0}, T, \delta\rangle$ with $0 \leq z<p$ veto players and an agenda $A=(1, \ldots, p)$ admits the ex-ante subgame perfect equilibrium given in Tables 4 and 5 , and results in immediate agreement.

Proof The proof is based on backward induction. For the last time period $t=T$, the equilibrium shares will be $(0, \ldots, 0,1)$. For $t=T-1$, the shares will be $\left(0, \ldots, 0,1-\delta_{p}, \delta_{p}\right)$ if $p \in Z$ (i.e., $p$ is a Bayesian veto player), and $(0, \ldots, 0,1,0)$ otherwise. Note that the set $Z$ in Theorem 1 is the set of veto players but here, $Z$ is the set of Bayesian veto players. Given this, the equilibrium for any time period $t$ depends on which players are Bayesian veto players and which ones are not. Thus, in each time period, the proposing player will need to give to every Bayesian veto player his discounted share for the next time period, and nothing to the Bayesian non-veto players. The rest of the proof follows from the proof for Theorem 1 .

Theorem 3 allows us to conclude that Observation 2 of Section 3.1 also holds in this case. In addition, the theorem leads us to the following observation:

Observation 3 A player's equilibrium share depends not on his weight but on whether he is a Bayesian veto player or not. For the agenda $(1, \ldots, p)$, the first mover (regardless of whether he is a Bayesian veto player or not) will get a non-zero share in the pie. Every Bayesian veto player will get a non-zero share in the pie. None of the Bayesian non-veto players in $\{2, \ldots, p\}$ will get any share (indeed, this is what we saw in Example 3: player 2, the only Bayesian non-veto player, got nothing and the pie was split between the two veto players). If there are no Bayesian veto players (i.e., $z=0$ ), then the first mover will get the entire pie and the rest will get nothing.

Theorem 4 The equilibrium shares for the first time period can be computed in $\mathcal{O}\left(b^{2} p^{2}+m p\right)$ time.

Proof The only difference between this proof and that for Theorem 2 is that, for the latter, it takes $\mathcal{O}(p)$ time find which of the p players are veto. But, for imperfect information, it takes $\mathcal{O}\left(b^{2} p^{2}\right)$ time. The rest of the proof follows from Theorem 2.

\section{The Noncooperative Equilibrium and the Core}

Following [22], we define the ex-ante core of a Bayesian WVG as follows. An allocation $x$ is in the ex-ante core of a Bayesian game $G=(A, W, B, q)$ if it is Pareto optimal, individual rational, and for each $C \subseteq P, \sum_{i \in C} x_{i} \geq \bar{v}(C)$. This definition covers both perfect and imperfect information settings (recall that for the former setting $b=1$ and for the latter $b>1$ ).

Let $x(B)$ denote the equilibrium allocation for $t=1$ for the imperfect information case. Then, the conditions for the non-cooperative equilibrium to be in the 


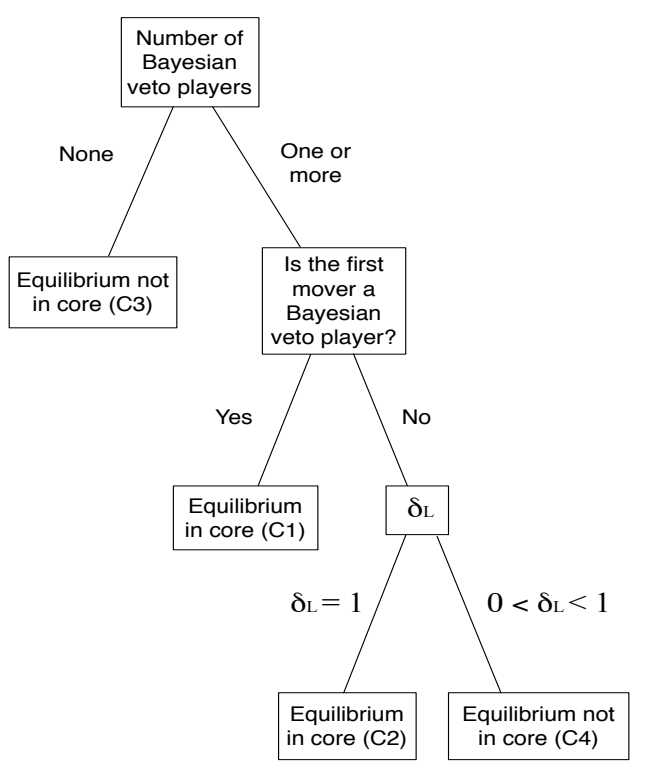

Fig. 1 A decision tree for deciding whether the non-cooperative equilibrium is in the core or not.

ex-ante core of $G=(A, W, B, q)$ are given in Theorem 5. Those conditions when it is not in the core are given in Theorem 6. Note that Theorems 5 and 6 together cover all possible bargaining games. This is demonstrated in the decision tree of Figure 1 (recall from Section 2 that for any player $i, 0<\delta_{i} \leq 1$ ). In these theorems, $1 \leq L \leq p$ will denote the last Bayesian veto player on the agenda, i.e., all the players $L+1, \ldots, p$ will be Bayesian non-veto players.

Theorem 5 The noncooperative equilibrium allocation $x(B)$ will be in the ex-ante core of the Bayesian voting game $G=(A, W, B, q)$ with $0<z<p$ veto players if

C1 the first mover is a Bayesian veto player, or

$C 2$ the first mover is a Bayesian non-veto player and the discount factor for the last

Bayesian veto player on the agenda is $\delta_{L}=1$.

Proof As per Observation 2 (note that both, Theorem 1 for perfect information and Theorem 3 for imperfect information, lead to Observation 2), the equilibrium solution is IR and PO. Thus, we need to prove that, for each $C \subseteq P, \sum_{i \in C} x_{i} \geq \bar{v}(C)$. We will do this first for the condition Cl. Since $0<z<p$, we know that there is at least one Bayesian veto player. Given this, as per Observation 3, the pie will be split only between the Bayesian veto players. Also, as per Observation 3, none of the Bayesian non-veto players will get any share. Now, the only Bayesian winning coalitions are those that contain all the Bayesian veto players. Thus, for every $C \in$ $S_{w}, \sum_{i \in C} x_{i}(B)=1$ and $\bar{v}(C)=1$. In addition, for every losing coalition $C \in S_{l}$, $0 \leq \sum_{i \in C} x_{i}(B)<1$ and $\bar{v}(C)=0$. It follows that, for the condition $C 1, x(B)$ is in the ex-ante core. 
Next, consider the condition C2 for which the first mover is a Bayesian non-veto player and the last veto player's discount factor is $\delta_{L}=1$. As per Table 5, only those players that are in $\left\{A_{1}\right\} \cup Z$ will get a non-zero share while the rest get nothing in the bargained agreement. In addition, as per Table 5, the last veto player will get a $100 \%$ of the pie at time $(m-1) \cdot p+L$. Moreover, since $\delta_{L}=1$, his share for all the previous time periods will remain the same. Thus, at $t=1$, the last veto player will get the entire pie and the remaining players will get nothing. Since every winning coalition must contain the Bayesian veto player $L$, for every $C \in S_{w}, \sum_{i \in C} x_{i}(B)=1$ and $\bar{v}(C)=1$. In addition, for every losing coalition $C \in S_{l}, 0 \leq \sum_{i \in C} x_{i}(B)<1$ and $\bar{v}(C)=0$. It follows that, for the condition $C 2, x(B)$ is in the ex-ante core.

Theorem 6 The noncooperative equilibrium $x(B)$ will not belong to the ex-ante core of the Bayesian voting game $G=(A, W, B, q)$ if

$C 3$ there are no Bayesian veto players in $G$, or

C4 the discount factor for the last Bayesian veto player is $0<\delta_{L}<1$ and the first mover is a Bayesian non-veto player.

Proof Consider the condition C3 first. If there are no Bayesian veto players, then, as per Observation 3, the first mover will get the entire pie. Since there are no veto players, the first mover will be a non-veto player. Not every winning coalition will contain the first mover. This means that there will be winning coalitions $C \in S_{w}$ such that $\sum_{i \in C} x_{i}(B)=0$ and $\bar{v}(C)=1$. Clearly, for the condition $C 3, x(B)$ will not be in the ex-ante core.

Consider the condition C4. As per Observation 3, the non-veto first mover will get a non-zero share. However, since he is non-veto, there will be winning coalitions that do not include the first mover. In other words, the coalition $A \backslash\{1\}$ will be ex-ante winning, i.e., $\bar{v}(A \backslash\{1\})=1$ but $\sum_{i \in A \backslash\{1\}} x_{i}(B)<1$. Thus, for the condition C4, the noncooperative equilibrium will not be in the ex-ante core.

\section{The Noncooperative Equilibrium and the Nucleolus}

The nucleolus [31] is a solution concept that defines a unique outcome for a game. It is based on the notion of excess. In the context of a Bayesian weighted voting game $G=\langle A, W, B, q\rangle$, we define excess as follows. For an allocation $x$ and a coalition $C \subseteq A$, the ex-ante excess $\varepsilon(C, x)$ is equal to $\bar{v}(C)-x(C)$ where $x(C)=$ $\sum_{i \in C} x_{i}$. Any allocation $x$ generates a $2^{p}$ dimensional ex-ante excess vector $\varepsilon(x)=$ $\left(\varepsilon\left(C_{1}, x\right), \ldots, \varepsilon\left(C_{2^{p}}, x\right)\right)$ where $C_{1}, \ldots, C_{2^{p}}$ is the list of all subsets of $P$ ordered by their excess for $x$, from the largest to the smallest: $\bar{v}\left(C_{i}\right)-x\left(C_{i}\right) \geq \bar{v}\left(C_{j}\right)-x\left(C_{j}\right)$ for any $1 \leq i \leq j \leq 2^{p}$. Two ex-ante excess vectors can be compared lexicographically: given two allocations $x$ and $y$ we say $\varepsilon(x)$ is lexicographically smaller than $\varepsilon(y)$ if there exists an $i \in\left\{1, \ldots, 2^{p}\right\}$ such that the first $i=1$ entries of $\varepsilon(x)$ and $\varepsilon(y)$ are equal, but the $i$ th entry of $\varepsilon(x)$ is smaller than the $i$ th entry of $\varepsilon(y)$; if this is the case, we write $\varepsilon(x)<_{\text {lex }} \varepsilon(y)$. We extend this notation to $\varepsilon(x) \leq_{l e x} \varepsilon(y)$ for $\varepsilon(x)<_{\text {lex }} \varepsilon(y)$ or $\varepsilon(x)=\varepsilon(y)$. 


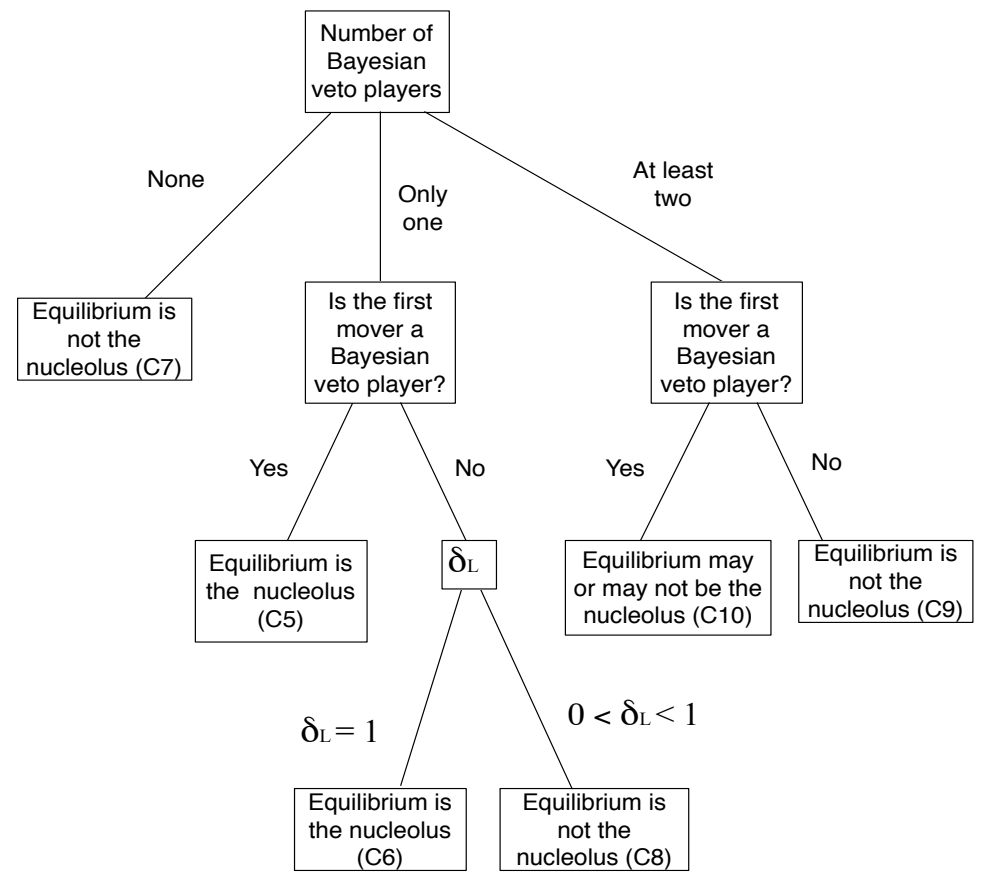

Fig. 2 A decision tree for deciding whether the non-cooperative equilibrium is the nucleolus or not.

An imputation is an individual rational allocation $x$ such that $\sum_{i \in A} x_{i}=v(A)$. The ex-ante nucleolus of a game $G=\langle A, W, B, q\rangle$ is an imputation $\eta=\left(\eta_{1}, \ldots, \eta_{p}\right)$ that satisfies $\varepsilon(\eta) \leq_{l e x} \varepsilon(x)$ for any other imputation $x$. We are now ready to demonstrate the relation between $\eta$ and the bargaining equilibrium $x(B)$.

Theorem 7 The noncooperative equilibrium $x(B)$ will be the ex-ante nucleolus of a Bayesian voting game $G=(A, W, B, q)$ if

C5 there is only one Bayesian veto player in $G$ who is the first mover, or

C6 there is only one Bayesian veto player in $G$ whose discount factor is $\delta_{L}=1$.

Proof Consider the condition C5. As per Observation 3, the veto player will get the entire pie. For each winning coalition $C \in S_{w}$ we get $\varepsilon(C, x(B))=0$ and for any losing coalition $C \in S_{l}$ we get $\varepsilon(C, x(B)) \leq 0$. Then, consider any allocation $y$ that gives a strictly positive share to one or more non-veto players. For any winning coalition $C \in S_{w}$ that does not contain a non-veto player with a strictly positive allocation, the excess will be $\varepsilon(C, y)>0$. It follows that $\varepsilon(x(B)) \leq_{l e x} \varepsilon(y)$ for any imputation $y$, i.e., $x(B)$ is the nucleolus of $G$.

Next, consider the condition C6. As per Table 5, only those players that are in $\left\{A_{1}\right\} \cup Z$ will get a non-zero share while the rest will get nothing in the bargained agreement. Also, as per Table 5, the veto player will get a $100 \%$ of the pie at time $(m-1) \cdot p+L$. Moreover, since $\delta_{L}=1$, his share for all the previous time periods 
will remain the same. Thus, at $t=1$, he will get the entire pie and the remaining players will get nothing. The rest of the proof is analogous to that for the condition C5

Theorem 8 The noncooperative equilibrium $x(B)$ will not be the ex-ante nucleolus of a Bayesian voting game $G=(A, W, B, q)$ if

$C 7$ there are no Bayesian veto players in $G$, or

$C 8$ there is only one Bayesian veto player in $G$, his discount factor is $0<\delta_{L}<1$, and he is not the first mover, or

C9 there are $1<z<p$ Bayesian veto players in $G$ and the first mover is a Bayesian non-veto player.

Proof See Appendix A.

Theorem 9 The noncooperative equilibrium $x(B)$ may or may not be the ex-ante nucleolus of a Bayesian voting game $G=(A, W, B, q)$ if

C10 there are $1<z<p$ Bayesian veto players in $G$ and the first mover is a Bayesian veto player.

Proof See Appendix A.

Theorems 7, 8, and 9 together cover all possible bargaining games. This is demonstrated in the decision tree of Figure 2. These results, and also those for the core demonstrate that, under certain conditions, there is no difference between noncooperative and cooperative approaches, since they both result in the same outcome.

\section{The Relation Between Agenda Position and Equilibrium Share}

From Table 5, it is evident that all the non-veto players except the first mover get no share in the pie, and that the first mover and all the Bayesian veto players get a nonnegative share in the pie. Furthermore, the equilibrium shares for the first mover and the veto players depend on their position on the agenda $A$, their discount factors, and the deadline $T=m \cdot p$. The purpose of this section is to investigate how a player's ex-ante equilibrium share is affected by his position on the agenda.

We will conduct this analysis by first assuming homogeneous discount factors, i.e., all the players have the same discount factor $\delta$. In Theorem 10 we characterize those $\delta$ for which the equilibrium shares of the players in $\left\{A_{1}\right\} \cup Z$ decrease monotonically as we go down from the first to the last position on the agenda. Then, towards the end of this section, we will consider heterogenous discount factors and determine the position that will be best for a Bayesian veto player who is patient (i.e., whose discount factor is one) and that for a Bayesian veto player who is very impatient (i.e., whose discount factor tends to zero). Finally, in Theorem 11 we will prove that, for heterogeneous discount factors and one bargaining cycle, each player's share is increasing in his discount factor. 
Theorem 10 Assume that all the players in a game $B G=\langle A, W, B, q, \mathbb{O}, T, \delta\rangle$ with zero conflict point have a homogeneous discount factor $\delta \in\left(0, \frac{1}{2}\right)$. Then, the equilibrium shares for the first mover and the z veto players decrease monotonically as we go down the agenda from the first to the last position. This is regardless of the distances $d_{0}^{1}, \ldots, d_{z}^{p}$, the number of players $p$, the number of veto players $z$, and the deadline $T$.

Proof Consider a time period $1 \leq t<p$ and suppose player $i$ is the proposer. We know that in the equilibrium for time $t+1$, the pie will be fully allocated between $a$ subset of the players in A. We also know that each player's utility is discounted by $\delta$ in each time period. Thus, at time $t$, the total allocation to the players in $A \backslash\{i\}$ will be $\delta$ meaning that i's share will be $(1-\delta)>1 / 2$. Thus, the proposer alone will get more than the cumulative shares of all the other players. Further, only the proposer and the veto players will get a non-zero share in the pie. It follows that the equilibrium shares for the first mover and the z veto players decrease monotonically as we go down the agenda from the first to the last position.

Theorem 10 shows monotonicity for $\delta \in\left(0, \frac{1}{2}\right)$. For other $\delta$, the equilibrium shares may vary non-monotically as we go down the agenda. We will demonstrate this through simulations. The setting for the simulations is described in Tables 6, 7, and 8. We consider games with $p=5$ players (see Table 6 ), $p=15$ players (see Table 7), and $p=25$ players (see Table 8 ). For each $p$, we vary the number of veto players, their positions on the agenda, the number of bargaining cycles (recall that the bargaining deadline is $T=m \cdot p$ where $m$ is the number of bargaining cycles). For each row of each of these three tables, we vary the discount factor $\delta$ between 0 and 1 , and determine a factor $\Delta$ such that for any $\delta<\Delta$, the equilibrium shares of the players in $\left\{A_{1}\right\} \cup Z$ decrease monotonically as we move from the first to the last position on the agenda. But for any $\delta \geq \Delta$, this monotonicity is lost. The discount factor $\Delta$ for each row in each of the Tables 6 to 8 is listed as the last column of that table. Note that, for each row of each of these three tables, $\Delta \geq 0.5$. These results correspond to what we proved in Theorem 10.

The monotonic decrease for $\delta<\Delta$, and non-monotonicity for $\delta \geq \Delta$ is illustrated in Figures 3 to 5 . Figure 3 corresponds to a specific row of Table 6, Figure 4 to a specific row of Table 7, and Figure 5 to a specific row of Table 8.

In more detail, Figure 3 is a plot of the equilibrium shares for a $p=5$ player game with one veto player at position three on the agenda and for $\delta=0.1$. For this game, we get $\Delta=0.7$ from Table 6 . The plot in Figure 3 for $\delta=0.1$ corresponds to $\delta<\Delta$ and there is a monotonic decrease in the equilibrium shares of the players in $\left\{A_{1}\right\} \cup Z$ (as proven in Theorem 10). However, in the same figure, for $\delta=0.71$ (i.e., $\delta>\Delta$ ) the equilibrium shares do not decrease monotonically.

Figure 4 is for $p=15$ player games with 8 veto players occupying positions 8 to 15 on the agenda. For this game, we get $\Delta=0.5$ from Table 7 . Notice the monotonicity in Figure 4 for $\delta=0.1$ (i.e., for $\delta<\Delta$ ) and the non-monotonicity for $\delta=0.9$ (i.e., for $\delta>\Delta$ ).

Figure 5 is for $p=25$ player games with 13 veto players occupying positions 13 to 25 on the agenda. For this game, we get $\Delta=0.58$ from Table 8 . Notice the 

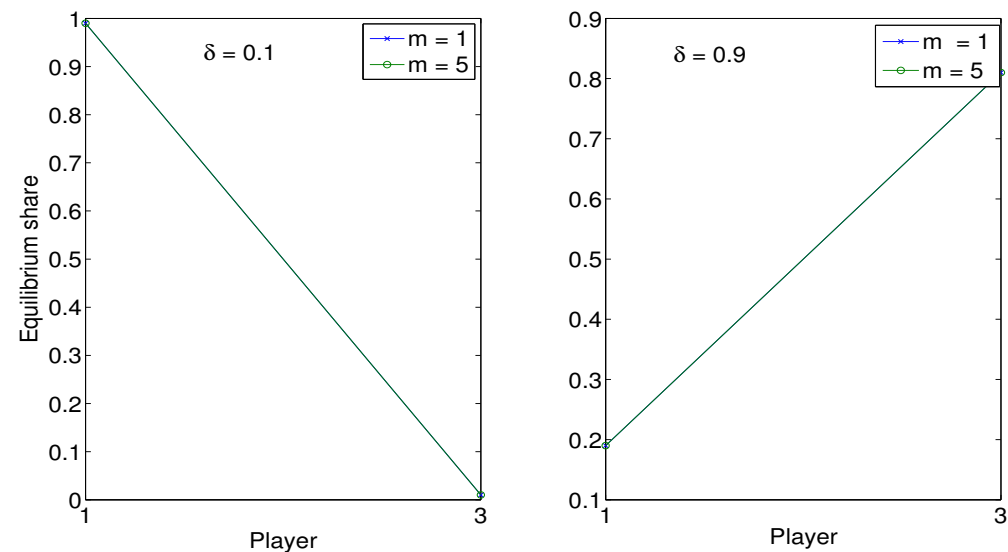

Fig. 3 The equilibrium shares for the first mover (i.e., Player 1) and the veto player (i.e., Player 3) for $p=5$ player games.
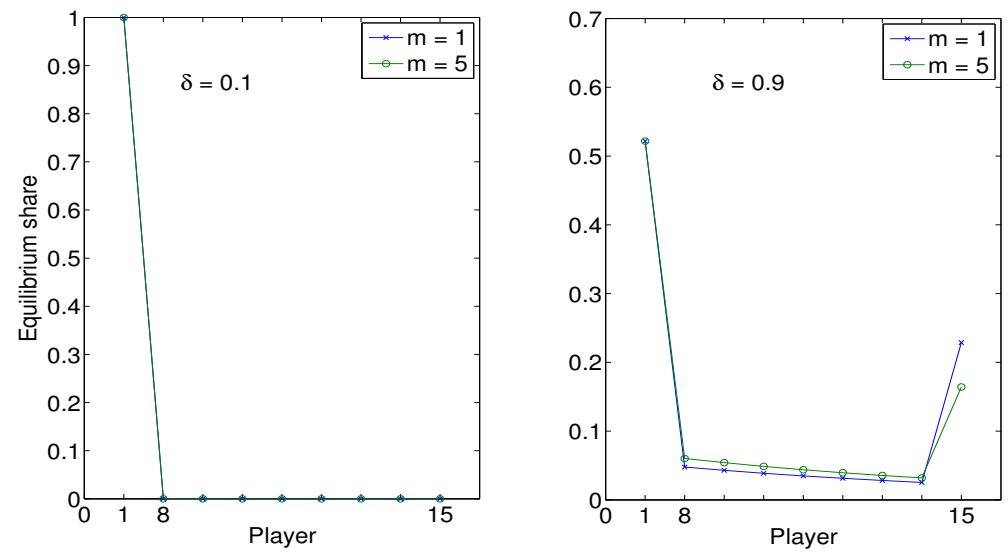

Fig. 4 The equilibrium shares for the first mover (i.e., Player 1) and the veto players (i.e., Players 8 to 15) for $p=15$ player games.

monotonicity in Figure 5 for $\delta=0.1$ (i.e., for $\delta<\Delta$ ) and the non-monotonicity for $\delta=0.9$ (i.e., for $\delta>\Delta$ ).

The above analysis leads us to the following observation:

Observation 4 For $\delta \in\left[\frac{1}{2}, 1\right]$, the equilibrium shares of the players in $\left\{A_{1}\right\} \cup Z$ may vary non-monotonically as we go down the agenda.

Let us now consider the case of heterogeneous discount factors. From Sections 3.1 and 3.2, we know that a non-veto player can get a non-zero share in the pie only if he is the first mover. 

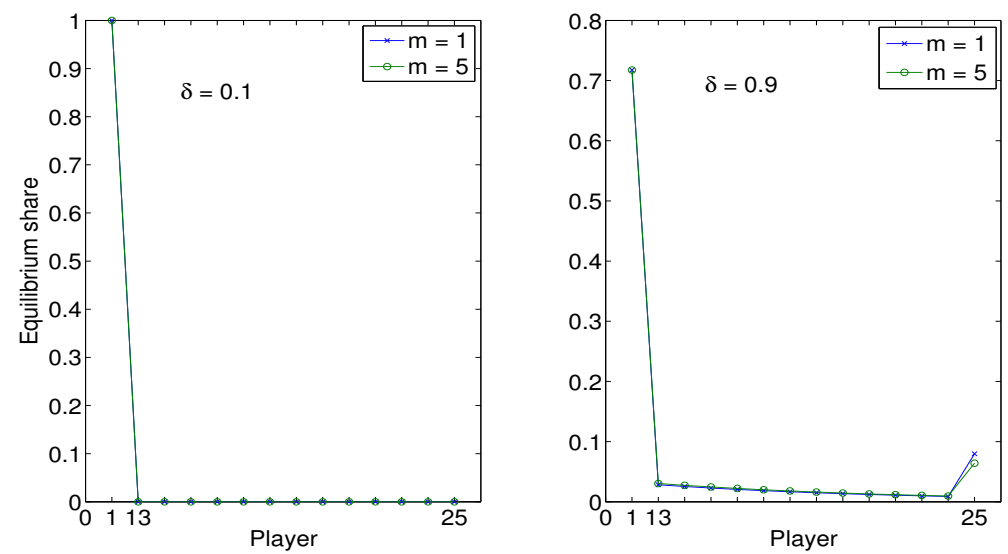

Fig. 5 The equilibrium shares for the first mover (i.e., Player 1) and the veto players (i.e., Players 13 to 25) for $p=25$ player games.

Observation 5 The first agenda position is the best for any non-veto player.

For a veto player, the best agenda position, in general, depends on his own discount factor and those of others, the number of veto and non-veto players, and the number of bargaining cycles. However, if a veto player is patient or else very impatient, we observe the following.

Observation 6 For a veto player with a discount factor of one, it is best to be the last veto player on the agenda. The actual position does not matter as long as all the other veto players precede him on the agenda. By being the last veto player, he can secure the entire pie for himself. But if there were veto players after him on the agenda, his share would be less than one since he would need to give the subsequent veto players their discounted shares and only keep the remaining pie for himself.

Observation 7 For a very impatient veto player, say $i$, with a discount factor suffciently close to zero, it is best to be the first mover. By sufficiently close to zero we mean that $\delta_{i}<1-\bar{\delta}$ where $\delta_{i}$ denotes the veto player's discount factor and $\bar{\delta}$ the discount factor for the most patient among the remaining veto players. The upper bound for $i$ 's share if he is not first mover will be $\delta_{i}$. We get this upper bound when $i$ is the second mover and he gets the entire pie in the equilibrium for the second time period $^{3}$. Next, $1-\bar{\delta}$ is the lower bound for $i$ 's share if he is the first mover. As first mover, $i$ 's share will be $1-\sum_{j \in Z \backslash i} \delta_{j} \cdot x_{j}$ where $x_{j}$ denotes player $j$ 's equilibrium share for the second time period. The upper bound for $\sum_{j \in Z \backslash i} \delta_{j} \cdot x_{j}$ is $\bar{\delta} \sum_{j \in Z \backslash i} x_{j}$. Since the pie is unit sized, the upper bound for $\bar{\delta} \sum_{j \in Z \backslash i} x_{j}$ will be $\bar{\delta}$. It follows that,

\footnotetext{
3 If the veto player $i$ occupied an agenda position, say $j$ (where $3 \leq j \leq m$ ), then even if he were to get the entire pie in the equilibrium for the $j$ th time period, his share for the first time period would be $\delta_{i}^{j-1}$. In other words, we get the upper bound of $\delta_{i}$ when player $i$ is the second mover.
} 
for $\delta_{i}<1-\bar{\delta}$ (i.e., $\delta_{i}$ is sufficiently close to zero), it is best for player $i$ to be the first mover.

Theorem 11 For a bargaining game with heterogeneous discount factors and one cycle (i.e., $m=1$ ), the share of each veto player who is not the first mover is increasing in his discount factor. The share of a veto player who is the first mover is independent of his discount factor.

Proof From Observation 1, we know that each non veto player who is not the first mover will get no share. Since $m=1$, the first mover's share will not be discounted and therefore his utility will depend only on the discount factors of the subsequent veto players on the agenda but not on his own discount factor. At time $1<t \leq p$, none of the first $t-1$ movers will get any share, and the share (say $x$ ) of a veto player in agenda position $t$ will depend not on his own discount factor but only on the discount factors of the subsequent veto players on the agenda. Then, player t's share for the first time period will be $x \cdot \delta_{t}^{t-1}$ and therefore increasing in $\delta_{t}$.

We know that for a game with heterogeneous discount factors and no veto players, the first mover will get the entire pie. Thus, the following observation:

Observation 8 For a bargaining game with heterogenous discount factors and no veto players, a player's share depends only on his agenda position, and is independent of i) his weight and the weights of the other players and ii) his discount factor and the discount factors of the other players.

\section{A Non-zero Conflict Point for the Bargaining Game}

For the bargaining game defined in Section 2.2, all the players get nothing if they fail to reach an agreement within $T$ time periods. That is, the conflict point was $\mathbb{O}=\mathbf{0}$. Now, suppose that we change the conflict point from $\mathbb{O}=\mathbf{0}$ to $\mathbb{O}=\alpha$ : instead of giving nothing, we give a constant share $\alpha_{i} \geq 0$ (with $\sum_{i=1}^{p} \alpha_{i}=1$ ) to each player $i \in P$ at time $T+1$. These shares could, for instance, be determined by a neutral arbitrator and made known to the players at the start of noncooperative bargaining.

The notation $\alpha>\mathbf{0}$ will mean that, for each $1 \leq i \leq p, \alpha_{i}>0$, and $\alpha \geq \mathbf{0}$ will mean that, for each $1 \leq i \leq p, \alpha_{i} \geq 0$. Given this new definition of the conflict point, let us first determine the equilibrium offer for the following example:

Example 4 There are three players $P=\{1,2,3\}$, with weights $W=(2,1,2)$. The quota is $q=4$, the deadline is $T=3$, the agenda is $A=(1,2,3)$, and the conflict point is $\alpha=(1 / 3,1 / 3,1 / 3)$. The discount factors are $\delta_{1}=\delta_{2}=\delta_{3}=1 / 2$.

For the last time period, the proposer (i.e., player 3) will give a non-zero share to those players he needs to form a winning coalition and nothing to the others. Since player 3 needs player 1 to form a winning coalition, he will give to player 1 his discounted share (i.e., 1/6) and to player 2 , he will give nothing (since player 3 does not need player 2 to form a winning coalition). Thus, the equilibrium offer for $T$ will be $(1 / 6,0,5 / 6)$ and this will be accepted by player 1 . Going backwards, we get $(19 / 24,0,5 / 24)$ as the equilibrium agreement for the first time period. 
Finding the equilibrium for $T$ was easy for the above example because there were only 3 players. However, in general, this problem will be computationally hard as is demonstrated in Theorem 12.

Theorem 12 If $\alpha \geq 0$, then the problem of computing an equilibrium offer for $B G=$ $\langle A, W, B, q, \alpha, T, \delta\rangle$ is NP-hard even under the perfect information assumption.

Proof At $T+1$, each player $i \in A$ will get a utility of $\alpha_{i} \cdot \delta_{i}^{T}$. Consider time $T$. The proposer (i.e., player $p$ ) will consider all those winning coalitions $C \subseteq A$ that he is a member of, and for each such $C$, his optimal offer at $T$ will be an $x$ such that $x_{j}^{T}=\alpha_{j} \cdot \delta_{j}$ for each $j \in C \backslash\{p\}, x_{j}^{T}=0$ for each $j \notin C$, and $x_{p}^{T}=$ $1-\sum_{j \in C \backslash\{p\}} \alpha_{j} \cdot \delta_{j}$. Thus, we must find a winning coalition that maximizes $x_{p}^{T}$ (or, equivalently, minimizes $\left.\sum_{j \in C \backslash\{p\}} \alpha_{j} \cdot \delta_{j}\right)$. If $\zeta$ is the binary string corresponding to $C$, then we must find a $\zeta$ that solves the problem $O_{T}$ :

$$
\begin{aligned}
& O_{T}: \quad \text { Minimize } \quad \sum_{i=1}^{p-1} \alpha_{i} \cdot \delta_{i} \cdot \zeta_{i} \\
& \text { s.t. } \quad \sum_{i=1}^{p-1} W_{i} \cdot \zeta_{i}+W_{p} \geq q \\
& \zeta_{i} \in\{0,1\} \text { for } 1 \leq i \leq p-1
\end{aligned}
$$

The problem $O_{T}$ is NP-hard by reduction from integer knapsack problem [17]; the weight (profit) of knapsack item $i$ is $w_{i}\left(\alpha_{i} \cdot \delta_{i}\right)$ and the knapsack capacity is $q-w_{p}$. Thus, even with perfect information, the equilibrium is hard to compute.

Note that, a crucial difference between the optimization problem $O_{t}$ in Table 4 and the optimization problem $O_{T}$ in Equation 2 is that, for the former, only the veto players need to be given a non-zero share but, for the latter, one or more non-veto players must be allocated a non-zero share because the conflict utilities are non-zero. Thus, for the latter, we need to find which non-veto players to include in the winning coalition. This difference makes the latter problem hard.

Although computing the equilibrium shares is hard, bargaining will end in immediate agreement (see Theorem 13) and only the first mover and the veto players will get non-negative shares while the rest of the players get nothing (see Theorem 14). It is interesting to note that, for both cases (i.e., zero conflict point and non-zero conflict point) only the players in $\left\{A_{1}\right\} \cup Z$ get non-negative shares while the remaining players get nothing. However, it is important to note that the actual shares need not be the same for these two cases. This can easily be verified for Example 4: for $\alpha=(1 / 3,1 / 3,1 / 3)$, the agreement will be $(19 / 24,0,5 / 24)$ and for $\alpha=(0,0,0)$ it will be $(3 / 4,0,1 / 4)$.

Theorem 13 A bargaining game $B G=\langle A, W, B, q, \alpha, T, \delta\rangle$ with $0 \leq z<p$ veto players and agenda $(1, \ldots, p)$ admits the ex-ante subgame perfect equilibrium given in Table 4 and results in immediate agreement.

Proof Here, the optimization problem for the last time period is as defined in Equation 2. For the previous time periods, it is as defined in Table 4. The rest of the proof is as in Theorem 3. 
Note that, Theorem 13 allows us to conclude that Observation 2 also holds for $\alpha \geq 0$. Next, we will prove Theorem 14 using the following notation: $N_{+}^{t}\left(N_{0}^{t}\right)$ will denote the set of non-veto players who get a positive (zero) share in the equilibrium for time period $1 \leq t \leq T+1$ and $n_{+}^{t}\left(n_{0}^{t}\right)$ will denote the cardinality of $N_{+}^{t}\left(N_{0}^{t}\right)$. As before, the agenda will be $A=(1, \ldots, p)$.

Theorem 14 For a bargaining game $B G=\langle A, W, B, q, \alpha, T, \delta\rangle$ with $0 \leq z<p$ veto players, the players in $\left\{A_{1}\right\} \cup Z$ get a non-negative share in equilibrium while the remaining players get nothing.

Proof Consider the last bargaining cycle, i.e., the time periods $t=(m-1) \cdot p+$ $1 \ldots, m \cdot p$. For a time period $t=(m-1) \cdot p+i$ (where $1 \leq i \leq p)$ of the last cycle, suppose that the proposer, i.e., player $i$, is a veto player. To form a winning coalition, $i$ will need the support of all the players in $Z \backslash\{i\}$. It follows that all the players in $Z \backslash\{i\}$ will get a non-zero share at $t$. In addition, player $i$ may also need the support of a subset of the non-veto players $(N)$. Thus, $i$ might need to include some/all of the players in $N_{0}^{t+1}$. If he needs more non-veto players than those in $N_{0}^{t+1}$, he will choose a subset from $N_{+}^{t+1}$. However, he need not include all the players from $N_{+}^{t+1}$. Those players from $N_{+}^{t+1}$ that are not necessary to form a winning coalition will get nothing in the equilibrium for $t$ even though they may get a non-zero share at $t+1$. It follows that the number of non-veto players who get nothing at time $t$ will be at least $\operatorname{MAX}\left(n_{+}^{t+1}-1,0\right)$. After giving all the required players their discounted shares, $i$ will keep the remaining pie.

Next, for a time period $t=(m-1) \cdot p+i$ of the last cycle, suppose that the proposer, i.e., player $i$, is a non-veto player. By the same argument, we conclude that the number of non-veto players who get nothing at time $t$ will be at least $\operatorname{MAX}\left(n_{+}^{t+1}\right.$ $1,0)$, and that player $i$ and all the players in $Z$ will get a non-zero share at $t$.

Thus, during every time period of the last cycle, the number of non-veto players who get a non-zero share will decrease by at least one relative to the next time period. Since $0 \leq n_{+}^{T+1} \leq n$ and $n \leq p$, we conclude that in the first time period of the last cycle, only those players in $\left\{A_{1}\right\} \cup Z$ will get a non-zero share and the rest will get nothing. By backward induction, we extend this conclusion to all the previous bargaining cycles.

Theorem 10 trivially extends to a non-zero conflict point.

Theorem 15 Assume that all the players in $B G=\langle A, W, B, q, \alpha, T, \delta\rangle$ have a homogeneous discount factor $\delta \in\left(0, \frac{1}{2}\right)$. Then, the equilibrium shares for the first mover and the $z$ veto players decrease monotonically as we go down the agenda from the first to the last position. This is regardless of the distances $d_{0}^{1}, \ldots, d_{z}^{p}$, the number of players $p$, the number of veto players $z$, and the deadline $T$.

Proof Only the first mover and the veto players get a positive share. The proof as that for Theorem 10.

Theorem 16 For a bargaining game with heterogeneous discount factors and one cycle (i.e., $m=1$ ), the share of each veto player who is not the first mover is increasing in his discount factor. The share of a veto player who is the first mover is independent of his discount factor. 
Proof From Theorem 14, we know that each non veto player who is not the first mover will get no share. Since $m=1$, the first mover's share will not be discounted and therefore his utility will depend only the discount factors of the subsequent veto players on the agenda but not on his own discount factor. At time $1 \leq t<p$, a proposing veto player's (i.e., Player t's) share will depend not on $\delta_{t}$ but on $\alpha_{t}$ and discount factors of the other players. Then, $t$ 's share for the first time period will be $\delta_{t}^{t-1}$ times his share for time $t$. Player $t$ 's share is therefore increasing in $\delta_{t}$.

Let us now look at the relation between the non-cooperative equilibrium and the core/nucleolus of the Bayesian voting game. Theorem 17 demonstrates that the bargaining equilibrium for a non-zero conflict point will not be in the core of the Bayesian voting game. Theorem 18 does the same for the nucleolus.

Theorem 17 For any game $B G=(A, W, B, q, \alpha>\boldsymbol{0}, T, \delta)$ with $0 \leq z<$ $p$ veto players, the bargained agreement does not belong to the ex-ante core of $(A, W, B, q)$.

Proof See Appendix A.

Theorem 18 For any voting game $B G=(A, W, B, q, \alpha>\boldsymbol{0}, T, \delta)$ with $0 \leq$ $z<p$ veto players, the bargained agreement will not be the ex-ante nucleolus of $(A, W, B, q)$.

Proof See Appendix A.

\section{Related Research}

The following are some prominent non-cooperative game-theoretic models of coalitional bargaining. These models had their beginnings in the pioneering work of Hurwicz [21] and are mostly multilateral extensions of Rubinstein's [29] two-player alternating offers game. These extensions include [20,32,3,19,24] and they have one common theme: they deal with the design of a non-cooperative game of sequential moves to yield a cooperative solution. After this research, it became apparent that the order in which players make moves is important in obtaining efficient outcomes. Consequently, [9] studied $n$-person unanimity bargaining with transferable utility, perfect information, discrete time periods, and a common discount factor. They showed conditions when stationary equilibria are efficient, and when such outcomes converge to core outcomes. $[38,25,23]$ conducted a similar analysis in the context of a nontransferable utility (NTU) game. Then, Perry and Reny [26] considered transferable utility games by treating time as a continuous variable. Furthermore, while the order of moves in $[9,25]$ is fixed exogenously, that in [26] is determined endogenously in a stationary equilibrium.

Bloch and Diamantoudi [5] studied a bargaining game similar to the one in [9] but in the context of hedonic games (which are a subclass of NTU games). They show that the existence of a no-delay stationary equilibrium hinges upon the fact that the hedonic game has a nonempty core. They also show conditions under which all stationary perfect equilibrium outcomes belong to the core. In our work, we use 
weighted voting games and the concept of subgame perfect equilibrium rather than stationary equilibrium.

A common feature of all the models cited above is that the underlying coalitional game has no externalities. In contrast, Bloch [4] studied noncooperative bargaining when the division of the coalitional surplus is fixed and the payoffs are defined relative to the whole coalition structure. This is an infinite horizon game in which the players do not discount the future. For an exogenous agenda, the first mover starts by proposing a coalition. If all prospective members accept, the coalition is formed. If a player rejects, she becomes the initiator in the next round. An important feature of the game is that, once a coalition is formed, the game is only played among the remaining players and established coalitions may not attract new members nor break apart. Hence, by agreeing to form a coalition, players commit to stay in that coalition. In this setting, Bloch was able to give conditions under which stationary equilibrium outcomes of the non-cooperative game are in the core of the cooperative game.

In the models cited above, the agenda is either defined exogenously or is determined endogenously in equilibrium. In contrast, Baron and Ferejohn [2] considered a more neutral rule for deciding this order. Specifically, every time a proposal must be made, the proposer is chosen randomly from the set of all players. In order for a proposal to be accepted, it must have majority support (in contrast, all the models cited above use the unanimity rule for accepting a proposal). All the players have unit weight and a common discount factor. The underlying coalitional game is that of transferable utilities. The key results of [2] are that, for finite horizon bargaining, there is a unique subgame perfect equilibrium that results in instant agreement. However, for the infinite horizon case, it is shown that any distribution of benefits can be supported by an SPE. The authors also demonstrate that the problem of multiplicity of equilibria can be overcome under certain conditions by resorting to stationary equilibrium. Specifically, they show uniqueness of equilibrium for symmetric games, i.e., games in which all the players have the same discount factor and they also have the same recognition probability (i.e, the probability of choosing a player as proposer in any time period is the same for all the players).

For stationary equilibrium, Eraslan [12] extended the uniqueness result of [2] to games with heterogeneous discount factors and different recognition probabilities. However, her analysis was restricted to voting games in which all the players have unit weight. Later, Snyder et al [35] extended Baron and Ferejohn's model [2] in which all the players have unit weight to more general weighted voting games. In more detail, the model investigated by Snyder et al is an infinite-horizon divide the dollar game without time discounting. Here, a random proposer is chosen with some probability at the beginning of each time period. Two specific cases are examined: one in which the recognition probabilities are uniform and the other in which they are proportional to voting weights. The authors showed a stationary no-delay equilibrium. They also showed that each players' expected equilibrium utility is proportional to her voting weight. This work was subsequently extended in [13] to games with more general recognition probabilities.

Chalkiadakis et al [8] studied coalitional bargaining for formation of multiple coalitions by making the perfect information assumption. Bargaining is conducted over a finite number of discrete rounds with a fixed agenda, i.e., one in which the 
players are arranged in decreasing order of their weights (in contrast to the fixed agenda considered in [8], in our work, we do not impose any such restriction on the agenda). The outcome of this game is an offer with majority support. The focus of this work is solely on comparing the efficiency of the equilibrium outcome with the global optimum. In contrast to [8], we focus on an imperfect information setting and address a number of research questions listed in Table 1.

For coalitional resource games (CRGs), a form of NTU games, Dunne et al. [11] analyzed a protocol for bargaining cooperation structures. Here, the bargaining is about how a group of agents will form coalitions in order to share a set of limited resources. In contrast, we focus on bargaining about how to divide a resource (i.e., a pie) between a group of agents. In addition, this work, in contrast to ours, is based on the perfect information assumption. Our work also differs from [11] in terms of the bargaining protocol: our protocol is based on majority support, but in [11], an offer is implemented only if all subsequent players on the agenda accept it. Dunne et al. [11] investigated the complexity of problems such as determining nonemptiness of the core of CRGs, and showed that the bargained outcome satisfies several desirable properties: Pareto optimality, dummy player, and pseudo-symmetry. We, on the other hand, address the questions listed in Table 1.

In contrast to our work, all the models cited above are based on the perfect information assumption. With regard to the bargaining game itself, our work is closest to that of Snyder et al [35], since we too use majority voting for accepting a proposal. However, there are also a number of crucial differences. First, they analyze infinite-horizon bargaining without time discounting in terms of stationary equilibrium strategies. Our model is a finite-horizon bargaining game with heterogeneous time discounting, for which we provide subgame perfect equilibrium strategies. Second, the agenda in [35] is set randomly but we consider an exogenously defined agenda. We do this because, in most contexts, the formation of the agenda is not random, but is shaped by political parties or legislative committees. Since our bargaining game is constrained by a deadline (as opposed to the infinite horizon game of [35]), we also showed how the conflict point affects the equilibrium. Third, unlike [35], our analysis uncovers the relation between the bargaining equilibrium and the core/nucleolus of the weighted voting game. Finally, unlike [35], our analysis sheds light on how a player's share is affected by his position on the agenda.

Duggan and Kalandrakis [10] studied a dynamic model of legislative bargaining by allowing the disagreement point to change during the course of negotiation. This model, although general, is hard to analyze; the authors did not solve the equilibrium outcome, they merely showed the existence of a stationary equilibrium.

A problem related to but distinct from the bargaining problem we study in this paper is that of fair division. In fair division, there is a resource (often referred to as a cake) and the problem is to devise a procedure for dividing the resource between a set of players according to some notion of fairness that all the players are assumed to agree to [6]. Procaccia [27] provides a recent survey of the literature on cake cutting. In contrast to the fair division problem, the bargaining problem we focus on is to find a division of the pie that will be agreeable to a majority of the players. In our bargaining model, any winning coalition is able to generate the pie. The aim then is to find a division through non-cooperative bargaining. During the process of bargain- 
ing, the individual players are the key decision makers in that each one of them makes proposals and also accepts/rejects the proposals made the others. We study the equilibrium properties of this noncooperative bargaining to show how the noncooperative equilibrium relates to cooperative notions of equilibrium.

Literature on markets comprised of multiple buyers and sellers where exchange of an item is between a buyer and a seller includes $[18,1]$. In contrast to this, our focus is on the division of a single resource between multiple players where the resource can be generated by several different coalitions.

\section{Conclusions and Future Work}

We have investigated strategic behavior in a finite-horizon noncooperative bargaining game with a deadline and heterogeneous discount factors. The outcome is an allocation with majority support. In the case of a conflict, i.e., there is no agreement within the deadline, all the players receive nothing. Majority support is modelled with a Bayesian weighted voting game with uncertainty over the players weights. The ex-ante Bayesian subgame perfect equilibrium for the noncooperative game can be computed in polynomial time and it results in a unique, instant, and Pareto optimal agreement. We showed the relation between the noncooperative equilibrium and the core, and the also the nucleolus, of the Bayesian voting game. Then, we showed how an individual's share for noncooperative bargaining is influenced by his position on the agenda. Finally, we showed that, if the conflict point is changed, the problem of computing an equilibrium becomes NP-hard even for the perfect information setting.

The key strengths of the bargaining model are that it supports a unique, instant, and Pareto optimal agreement regardless of whether the conflict point is zero or otherwise. In addition, for the zero conflict point, the equilibrium is polynomial time computable. For the non-zero conflict point, the problem of computing the equilibrium is NP-hard. Nevertheless, reduction from integer knapsack means that the problem can be solved in pseudo polynomial time. Another strength of the model is that, for the zero conflict point, it conditionally supports the core and the nucleolus of the Bayesian voting game. Perhaps a weakness of the model is that, regardless of the conflict point, none of the non-veto players who is not first mover will get any share of the pie. This is a key reason that, for a non-zero conflict point, the bargaining equilibrium does not support the core or the nucleolus of the weighted voting game.

A number of issues remain to be explored. For the case of non-zero conflict point, we showed that only the first mover and the veto players get a non-zero share in the pie. More research needs to be done to determine what happens to the shares of these players as we move from the first to the last position on the agenda (i.e., do the shares decrease monotonically as was the case for zero conflict point with a homogeneous discount factor?). Another direction for extension is to consider multiple pies as opposed to the single pie analysis conducted in this paper. Yet another possibility is to use a vector voting game (which is a generalised version of weighted voting games considered in this paper) for modelling majority support. 


\section{Acknowledgement}

We thank the reviewers for their detailed and insightful comments which helped us to clarify a number of concepts and also to simplify the proof of Theorem 10. Michael Wooldridge was supported by the ERC under Advanced Grant 291528 (RACE).

\section{References}

1. B. An, N. Gatti, and V. Lesser. Extending the alternating-offers bargaining in one-to-many and manyto-many settings. In Proc. IAT, pages 423-426, 2009.

2. D. Baron and J. Ferejohn. Bargaining in legislatures. American Political Science Review, 83(4):11811206, 1989.

3. K. Binmore. Bargaining and coalitions. In A. Roth, editor, Game Theoretic Models of Bargaining. Cambridge University Press: Cambridge, 1985.

4. F. Bloch. Sequential formation of coalitions in games with externalities and fixed payoff division Games and Economic Behavior, 14:19-123, 1996.

5. F. Bloch and E. Diamantoudi. Noncooperative formation of coalitions in hedonic games. International Journal of Game Theory, 40:263-280, 2011.

6. S. Brams and A. Taylor. Fair division: From cake cutting to dispute resolution. Cambridge University Press, 1996.

7. S. Ceppi, N. Gatti, and C. Iuliano. Non-cooperative bargaining with arbitrary one-sided uncertainty. In Proc. Workshop on Agent Mediated Electronic Commerce, pages 1-14, 2011.

8. G. Chalkiadakis, E. Elkind, M. Polukarov, and N. R. Jennings. The price of democracy in coalition formation. In In Proc. of the Eighth International Joint Conference on Autonomous Agents and Multiagent Systems, pages 401-408, 2009.

9. K. Chatterjee, B. Dutta, D. Ray, and K. Sengupta. A noncooperative theory of coalitional bargaining. Review of Economic Studies, 60:463-477, 1993.

10. P. J. Duggan and T. Kalandrakis. Dynamic legislative policy making. Journal of Economic Theory, 147:1653-1688, 2011.

11. P. E. Dunne, S. Kraus, E. Manisterski, and M. Wooldridge. Solving coalitional resource games. Artificial Intelligence, 174:20-50, 2010.

12. H. Eraslan. Uniqueness of stationary equilibrium payoffs in the Baron-Ferejohn model. Journal of Economic Theory, 103:11-30, 2002.

13. H. Eraslan and A. McLennan. Uniqueness of stationary equilibrium payoffs in coalitional bargaining. Journal of Economic Theory, 148(6):2195-2222, 2013.

14. S. Fatima, S. Kraus, and M. Wooldridge. Principles of Automated Negotiation. Cambridge University Press, 2014.

15. S. S. Fatima, M. Wooldridge, and N. R. Jennings. Multi-issue negotiation with deadlines. Jnl. of AI Research, 27:381-417, 2006

16. F. Forges and R. Serrano. Cooperative games with incomplete information: Some open problems Social Science Research Network, 2011.

17. M. R. Garey and D. S. Johnson. Computers and Intractability. W. H. Freeman and Company, 1979.

18. N. Gatti. Extending the alternating offers protocol in the presence of competition: models and theoretical analysis. Ann Math Artif Intell, 55:189-236, 2009.

19. F. Gul. Bargaining foundations of the Shapley value. American Political Science Review, 57:81-95, 1989.

20. J. Harsanyi. An equilibrium-point interpretation of stable sets and a proposed alternative definition. Management Science, 20:1472-1495, 1974.

21. L. Hurwicz. On informationally decentralized systems. In R. Radner and C. McGuire, editors, Decisions and Organization. Amsterdam:North-Holland, 1972.

22. S. Ieong and Y. Shoham. Bayesian coalitional games. In Proc. AAAI, 2008.

23. K. Kultti and H. Vartiainen. Multilateral cooperative bargaining in a general utility space. International Journal of Game Theory, 39(4):677-689, 2010.

24. B. Moldovanu. Coalition-proof Nash equilibria and the core in three-player games. Games and Economic Behavior, 4:565-581, 1990. 
25. B. Moldovanu and E. Winter. Order independent equilibria. Games and Economic Behavior, 9:21-34, 1995.

26. M. Perry and P. Reny. A noncooperative view of coalition formation and the core. Econometrica, 62:795-817, 1994

27. A. Procaccia. Cake cutting: Not just child's play. Communications of the ACM, 56(7):78-87, 2013.

28. D. Ray. A Game-Theoretic Perspective on Coalition Formation. Oxford University Press, 2007.

29. A. Rubinstein. Perfect equilibrium in a bargaining model. Econometrica, 50(1):97-109, January 1982.

30. A. Rubinstein. A bargaining model with incomplete informations about time preferences. Econometrica, 53:1151-1172, 1985

31. D. Schmeidler. The nucleolus of a characteristic function game. SIAM Journal on Applied Mathematics, 17:1163-1170, 1969

32. R. Selten. A noncooperative model of characteristic function bargaining. In V. Bohm and H. Natchcamp, editors, Essays in Game Theory and Mathematical Economics in Honour of Oskar Morgenstern. Bibliographisches Institut, Manheim, 1981.

33. R. Serrano. Bargaining. The New Palgrave Dictionary of Economics, (2nd edition), 2005.

34. R. Serrano. Fifty years of the Nash program 1953 - 2000. Investigaciones Economicas, 29(2):219258,2005 .

35. J. Snyder, M. Ting, and S. Ansolabehere. Legislative bargaining under weighted voting. The American Economic Review, 95(4):981-1004, 2005.

36. I. Stahl. Bargaining Theory. Economics Research Institute, Stockholm School of Economics, Stockholm, 1972.

37. J. Sutton. Non-cooperative bargaining theory: An introduction. Review of Economic Studies, 53(5):709-724, 1986.

38. J. Vidal-Puga. Forming coalitions and the Shapley NTU value. European Journal of Operational Research, 190:659-671, 2008. 
Appendix

\section{A Proofs}

\section{Theorem 8}

Proof Consider the condition C7 first. If there are no Bayesian veto players, then, as per Observation 3 , the first mover (who is a non-veto player) will get the entire pie. Not every winning coalition will contain the first mover. This means that there will be winning coalitions $C \in S_{w}$ such that $\sum_{i \in C} x_{i}(B)=0$ and $\bar{v}(C)=1$. For such a winning coalition, $\varepsilon(C, x(B))=1$. Next, consider the allocation $y$ that gives a share of $1 / p$ to each player. For this allocation, the maximum possible excess with respect to any winning coalition $C \in S_{w}$ will be $\varepsilon(C, y)=1-1 / p$, and the excess for any losing coalition $C \in S_{l}$ will be $\varepsilon(C, y) \leq 0$. But we know that, in the excess vector $\varepsilon(x(B))$, at least element will be 1 . In other words, $\varepsilon(y)<_{\text {lex }} \varepsilon(x(B))$. The bargained allocation $x(B)$ therefore cannot be the nucleolus of $G$.

Next, consider the condition C8. Here, as per Observation 3, only the non-veto first mover and the veto player will each get a strictly positive share will the remaining players get nothing. The excess for any winning coalition $C \in S_{w}$ not containing the first mover will be $\varepsilon(C, x(B))>0$. Note that, there will be at least one such winning coalition. Then, consider the allocation $y$ that allocates the entire pie to the only veto player. Now, for every winning coalition $C \in S_{w}$ we get $\varepsilon(C, y)=0$, and for any losing coalition $C \in S_{l}$ we get $\varepsilon(C, y) \leq 0$. Clearly, $\varepsilon(y)<_{l e x} \varepsilon(x(B))$. The bargained allocation $x(B)$ therefore cannot be the nucleolus of $\bar{G}$.

Next, consider the condition $\mathrm{C} 9$ for which one of two possibilities can arise. One possibility is $0<$ $\delta_{L}<1$ and the other is $\delta_{L}=1$. Consider $0<\delta_{L}<1$. This means that the first mover will get a strictly positive share in the bargained agreement and, as a result, the cumulative share of all the veto players will be less than one. Since the first mover is a non-veto player, there will be at least one winning coalition $C$ not containing him. For such a coalition $C$, the excess will be $0<\varepsilon(C, x(B))<1$. Then, consider any allocation $y$ that equally allocates the entire pie between the veto players and gives nothing to the non-veto players. For each winning coalition $C \in S_{w}, \varepsilon(C, y)=0$. For any losing coalition $C \in S_{l}$, $\varepsilon(C, y) \leq 0$. Since the maximum in the excess vector $\varepsilon(x(B))$ is greater than the maximum in the excess vector $\varepsilon(y)$, we have $\varepsilon(y)<_{l e x} \varepsilon(x(B))$. The bargained allocation $x(B)$ therefore cannot be the nucleolus of $G$.

Next, consider $\mathrm{C} 9$ for $\delta_{L}=1$. In the bargained equilibrium, the last veto player on the agenda will get the entire pie and the rest of the players will get nothing. Thus, for each $C \in S_{w}$, we get $\varepsilon(C, x(B))=0$. Likewise, for each losing coalition $C$ that does not contain the last veto player on the agenda (there are $2^{p-1}$ such losing coalitions), we get $\varepsilon(C, x(B))=0$. Lastly, for each losing coalition $C$ that contains the last veto player on the agenda, we get $\varepsilon(C, x(B))=-1$. Thus, in the excess vector $\varepsilon(x(B))$, each of the the first $\left|S_{w}\right|+2^{p-1}$ entries will be zero and each of the remaining entries will be -1 . Then, consider the allocation $y$ that equally allocates the pie between the veto players and gives nothing to the non-veto players. For each winning coalition $C \in S_{w}$, we get $\varepsilon(C, y)=0$. For any losing coalition $C \in S_{l}$, $\varepsilon(C, y) \leq 0$. Specifically, for each losing coalition $C$ that does not contain any veto player (there are $2^{n}$ such losing coalitions), we get $\varepsilon(C, y)=0$. In addition, for any losing coalition $C$ containing up to $z-1$ veto players, we get $\varepsilon(C, y) \leq 0$. Finally, for each losing coalition containing all the $z$ veto players, we get $\varepsilon(C, y)=-1$. Thus, in the excess vector $\varepsilon(y)$, each of the the first $\left|S_{w}\right|+2^{n}$ entries will be zero, some of the following entries will be negative but greater than -1 , and all the remaining entries will be -1 . We are given that $z \geq 2$ meaning that $n<p-1$. It follows that $\varepsilon(y)<_{l e x} \varepsilon(x(B))$. The bargained allocation $x(B)$ therefore cannot be the nucleolus of $G$. $\square$

\section{Theorem 9:}

Proof The proof is comprised of two examples: one to illustrate that the bargaining equilibrium is the nucleolus of the WVG and the other to show that it is not. In the first example, there are 3 bargainers $A=$ $\{1,2,3\}$ where Player 1 and Player 3 are ex-ante Bayesian veto players and Player 2 is non-veto. The quota for the $G$ is $q=4$. The discount factors are $\delta_{1}=\delta_{2}=\delta_{3}=1 / 2$. The bargaining deadline is $T=3$ and the bargaining agenda is $(1,2,3)$. The bargained agreement for this example is $(3 / 4,0,1 / 4)$. The excess vector $\varepsilon(x(B))=(0,0,0,0,-1 / 4,-1 / 4,-3 / 4,-3 / 4)$. Consider the allocation $y=(1 / 2,0,1 / 2)$ for which the excess vector will be $\varepsilon(y)=(0,0,0,0,-1 / 2,-1 / 2,-1 / 2,-1 / 2)$. Since $\varepsilon(y)<_{\text {lex }}$ $\varepsilon(x(B))$, the bargaining equilibrium cannot be the nucleolus of $G$. 
The next example is the same as the one above except for the discount factor which is now $\delta_{1}=\delta_{2}=$ $\delta_{3}=1 / \sqrt{2}$. The bargained agreement for this example is $(1 / 2,0,1 / 2)$. The excess vector is $\varepsilon(x(B))=$ $(0,0,0,0,-1 / 2,-1 / 2,-1 / 2,-1 / 2)$. Consider any allocation $y=(a, b, c)$ such that $a \geq 0, b>0$, and $c \geq 0$. For any such allocation, the excess vector $\varepsilon(y)$ will contain at least one element that is strictly greater than zero, meaning that $\varepsilon(x(B))<_{l e x} \varepsilon(y)$. Next, consider any allocation $y=(a, 0,1-a)$ such that $a \geq 0$. For $1-a<a$, the excess vector will be $\varepsilon(y)=(0,0,0,0, a-1, a-1,-a,-a)$ where $a-1>-1 / 2$. For $1-a>a$, the excess vector will be $\varepsilon(y)=(0,0,0,0,-a,-a, a-$ $1, a-1)$ where $-a>-1 / 2$. Lastly, for $1-a=a$, we get $y=(1 / 2,0,1 / 2)$ which is the same as the bargained agreement. We conclude that $\varepsilon(x(B)) \leq_{l e x} \varepsilon(y)$ for all possible imputations $y$, i.e, the bargained agreement is the nucleolus of the WVG.

\section{Theorem 17:}

Proof Consider the following cases that cover the entire space of possible bargaining and Bayesian voting games:

1. There are no veto players, i.e., $z=0$ : From the bargaining equilibrium of Theorem 14, we know that the non-veto first mover will get the entire pie while the rest of the players will get nothing. Since $\alpha>0$, i.e., every player gets a strictly positive share in the event of a conflict, the bargained outcome will not be individual rational and therefore it will not belong to the ex-ante core of $G$.

2. There is at least one veto player, i.e., $0<z<p$ : Here, we must consider the following possibilities:

(a) The first mover is a veto player: Here, as per Theorem 14, each non-veto player will get nothing in the bargained outcome. Such an outcome is not individual rational and therefore it will not belong to the ex-ante core of $G$.

(b) The first mover is a non-veto player: Here, one of two possibilities can arise. One possibility is that the first mover is the only non-veto player. Now, if all the veto players have a discount factor of one, the first mover will get nothing, meaning the outcome will not be individual rational. Next, if at least one veto player's discount factor is less than one, the first mover will get a strictly positive share in the pie. Here, the total allocation for a winning coalition not containing the first mover (not every winning coalition will contain the first mover since he is a non-veto player) will be less than one. But the value of every winning coalition is one. Thus, the bargained outcome will not be in the core of $G$.

The other possibility is that the first mover is not the only non-veto player. As per Theorem 14 , only the players in $\left\{A_{1}\right\} \cup Z$ get a non-zero share while the others get nothing. But because $\alpha>\mathbf{0}$, the bargained outcome will not be individual rational and therefore it will not be in the core of $G$. $\square$

\section{Theorem 18:}

Proof Consider the following cases that cover the entire space of possible bargaining and Bayesian voting games:

1. There are no veto players, i.e., $z=0$ : From the bargaining equilibrium of Theorem 14, we know that the non-veto first mover will get the entire pie while the rest of the players will get nothing. Since $\alpha>0$, i.e., every player gets a positive share in the event of a conflict, the bargained outcome will not be individual rational and therefore cannot be the ex-ante nucleolus of $G$.

2. There is at least one veto player, i.e., $0<z<p$ : Here, we must consider the following possibilities:

(a) The first mover is a veto player: Here, as per Theorem 14, each non-veto player will get nothing in the bargained outcome. Such an outcome is not individual rational and therefore it cannot be the ex-ante nucleolus of $G$.

(b) The first mover is a non-veto player: Here, one of two possibilities can arise. One possibility is that the first mover is the only non-veto player. Now, if all the veto players have a discount factor of one, the first mover will get nothing, meaning the outcome will not be individual rational. Next, if at least one veto player's discount factor is less than one, the first mover will get a strictly positive share in the pie. Here, we have at least one winning coalition $C \in S_{w}$ for which the excess is $\varepsilon(C, x(B))>0$. Then, consider the allocation $y$ that allocates the pie equally between the veto players and gives nothing to the non-veto players. For each winning coalition $C \in S_{w}$, we get $\varepsilon(C, y)=0$. For each losing coalition $C \in S_{l}$, we get $\varepsilon(C, y) \leq 0$. It follows that $\varepsilon(y)<_{l e x} \varepsilon(x(B))$, i.e, the bargained agreement cannot be the nucleolus.

The other possibility is that the first mover is not the only non-veto player. Since only the players in $\left\{A_{1}\right\} \cup Z$ get a positive share, and $\alpha>\mathbf{0}$, the bargained outcome will not be individual rational and therefore it cannot be the nucleolus of $G$. $\square$ 


\section{B Simulation Results}

\begin{tabular}{|c|c|c|c|}
\hline $\begin{array}{l}\text { The number of } \\
\text { veto players } z\end{array}$ & $\begin{array}{l}\text { The deadline } \\
T=m \cdot p\end{array}$ & $\begin{array}{l}\text { The positions of the veto } \\
\text { players on the agenda }\end{array}$ & $\Delta$ \\
\hline \multirow{9}{*}{1} & \multirow{3}{*}{5} & 1 & 1 \\
\hline & & 3 & 0.7 \\
\hline & & 5 & 0.84 \\
\hline & \multirow{3}{*}{25} & 1 & 1 \\
\hline & & 3 & 0.7 \\
\hline & & 5 & 0.84 \\
\hline & \multirow{3}{*}{50} & 1 & 1 \\
\hline & & 3 & 0.7 \\
\hline & & 5 & 0.84 \\
\hline \multirow{9}{*}{3} & \multirow{3}{*}{5} & $1,2,3$ & 0.5 \\
\hline & & $3,4,5$ & 0.5 \\
\hline & & $1,3,5$ & 0.7 \\
\hline & \multirow{3}{*}{25} & $1,2,3$ & 0.54 \\
\hline & & $3,4,5$ & 0.52 \\
\hline & & $1,3,5$ & 0.93 \\
\hline & \multirow{3}{*}{50} & $1,2,3$ & 0.5 \\
\hline & & $3,4,5$ & 0.5 \\
\hline & & $1,3,5$ & 0.96 \\
\hline \multirow{9}{*}{4} & \multirow{3}{*}{5} & $1,2,3,4$ & 0.5 \\
\hline & & $1,2,4,5$ & 0.5 \\
\hline & & $2,3,4,5$ & 0.5 \\
\hline & \multirow{3}{*}{25} & $1,2,3,4$ & 0.61 \\
\hline & & $1,2,4,5$ & 0.6 \\
\hline & & $2,3,4,5$ & 0.61 \\
\hline & \multirow{3}{*}{50} & $1,2,3,4$ & 0.63 \\
\hline & & $1,2,4,5$ & 0.6 \\
\hline & & $2,3,4,5$ & 0.61 \\
\hline
\end{tabular}

Table 6 The discount factor $\Delta$ for various $p=5$ player games. For any $\delta<\Delta$, the equilibrium shares for the players in $\left\{A_{1}\right\} \cup Z$ decrease monotonically as we go down the agenda from the first to the last position. For $\delta \geq \Delta$, this monotonicity is lost. 


\begin{tabular}{|c|c|c|c|}
\hline $\begin{array}{l}\text { The number of } \\
\text { veto players } z\end{array}$ & $\begin{array}{l}\text { The deadline } \\
T=m \cdot p\end{array}$ & $\begin{array}{l}\text { The positions of the veto } \\
\text { players on the agenda }\end{array}$ & $\Delta$ \\
\hline \multirow{12}{*}{$\mathrm{P}_{\mathrm{P}}$} & \multirow{4}{*}{15} & 1 & 1 \\
\hline & & 2 & 0.5 \\
\hline & & 8 & 0.9 \\
\hline & & 15 & 0.95 \\
\hline & \multirow{4}{*}{75} & 1 & 1 \\
\hline & & 2 & 0.5 \\
\hline & & 8 & 0.9 \\
\hline & & 15 & 0.95 \\
\hline & \multirow{4}{*}{150} & 1 & 1 \\
\hline & & 2 & 0.5 \\
\hline & & 8 & 0.9 \\
\hline & & 15 & 0.95 \\
\hline \multirow{18}{*}{8} & \multirow{6}{*}{15} & $1, \ldots, 8$ & 0.5 \\
\hline & & $8, \ldots, 15$ & 0.5 \\
\hline & & $1,3,5,7,9,11,13,15$ & 0.7 \\
\hline & & $1,3, \ldots, 6,10,12,15$ & 0.5 \\
\hline & & $2,6, \ldots, 9,11,13,15$ & 0.61 \\
\hline & & $1,3,5,8, \ldots, 11,14$ & 0.54 \\
\hline & \multirow{6}{*}{75} & $1, \ldots, 8$ & 0.5 \\
\hline & & $8, \ldots, 15$ & 0.5 \\
\hline & & $1,3,5,7,9,11,13,15$ & 0.6 \\
\hline & & $1,3, \ldots, 6,10,12,15$ & 0.5 \\
\hline & & $2,6, \ldots, 9,11,13,15$ & 0.61 \\
\hline & & $1,3,5,8, \ldots, 11,14$ & 0.54 \\
\hline & \multirow{6}{*}{150} & $1, \ldots, 8$ & 0.5 \\
\hline & & $8, \ldots, 15$ & 0.5 \\
\hline & & $1,3,5,7,9,11,13,15$ & 0.98 \\
\hline & & $1,3, \ldots, 6,10,12,15$ & 0.6 \\
\hline & & $2,6, \ldots, 9,11,13,15$ & 0.61 \\
\hline & & $1,3,5,8, \ldots, 11,14$ & 0.54 \\
\hline \multirow{8}{*}{14} & \multirow{3}{*}{15} & $1,3, \ldots, 15$ & 0.5 \\
\hline & & $1, \ldots, 7,9, \ldots, 15$ & 0.5 \\
\hline & & $1, \ldots, 14$ & 0.5 \\
\hline & \multirow{3}{*}{75} & $1,3, \ldots, 15$ & 0.92 \\
\hline & & $1, \ldots, 7,9, \ldots, 15$ & 0.6 \\
\hline & & $1, \ldots, 14$ & 0.6 \\
\hline & \multirow{2}{*}{150} & $\begin{array}{c}1,3, \ldots, 15 \\
1, \ldots 7,9, \ldots, 15\end{array}$ & $\begin{array}{l}0.58 \\
0.61\end{array}$ \\
\hline & & $\begin{array}{c}1, \ldots, r, 9, \ldots, 10 \\
1, \ldots, 14\end{array}$ & $\begin{array}{l}0.61 \\
0.61\end{array}$ \\
\hline
\end{tabular}

Table 7 The discount factor $\Delta$ for $p=15$ player games. For any $\delta<\Delta$, the equilibrium shares for the players in $\left\{A_{1}\right\} \cup Z$ decrease monotonically as we go down the agenda from the first to the last position. For $\delta \geq \Delta$, this monotonicity is lost. 


\begin{tabular}{|c|c|c|c|}
\hline $\begin{array}{l}\text { The number of } \\
\text { veto players } z\end{array}$ & $\begin{array}{l}\text { The deadline } \\
T=m \cdot p\end{array}$ & $\begin{array}{l}\text { The positions of the veto } \\
\text { players on the agenda }\end{array}$ & $\Delta$ \\
\hline \multirow{12}{*}{1} & \multirow{4}{*}{25} & 1 & 1 \\
\hline & & 2 & 0.5 \\
\hline & & 13 & 0.94 \\
\hline & & 25 & 0.97 \\
\hline & \multirow{4}{*}{125} & 1 & 1 \\
\hline & & 2 & 0.5 \\
\hline & & 13 & 0.94 \\
\hline & & 25 & 0.97 \\
\hline & \multirow{4}{*}{250} & 1 & 1 \\
\hline & & 2 & 0.5 \\
\hline & & 13 & 0.94 \\
\hline & & 25 & 0.97 \\
\hline \multirow{18}{*}{13} & \multirow{6}{*}{25} & $1, \ldots, 13$ & 0.5 \\
\hline & & $13, \ldots, 25$ & 0.58 \\
\hline & & $1,3,5,7,9,11,13,15,17,19,21,23,25$ & 0.6 \\
\hline & & $1,3,5, \ldots, 12,17,18,25$ & 0.5 \\
\hline & & $1,4,5,9, \ldots, 16,20,24$ & 0.5 \\
\hline & & $1,4, \ldots, 6,15, \ldots, 22,25$ & 0.5 \\
\hline & \multirow{6}{*}{125} & $1, \ldots, 13$ & 0.5 \\
\hline & & $13, \ldots, 25$ & 0.58 \\
\hline & & $1,3,5,7,9,11,13,15,17,19,21,23,25$ & 0.9 \\
\hline & & $1,3,5, \ldots, 12,17,18,25$ & 0.5 \\
\hline & & $1,4,5,9, \ldots, 16,20,24$ & 0.6 \\
\hline & & $1,4, \ldots, 6,15, \ldots, 22,25$ & 0.5 \\
\hline & \multirow{6}{*}{250} & $1, \ldots, 13$ & 0.5 \\
\hline & & $13, \ldots, 25$ & 0.58 \\
\hline & & $1,3,5,7,9,11,13,15,17,19,21,23,25$ & 0.9 \\
\hline & & $1,3,5, \ldots, 12,17,18,25$ & 0.5 \\
\hline & & $1,4,5,9, \ldots, 16,20,24$ & 0.6 \\
\hline & & $1,4, \ldots, 6,15, \ldots, 22,25$ & 0.6 \\
\hline \multirow{9}{*}{24} & \multirow{3}{*}{25} & $1, \ldots, 24$ & 0.6 \\
\hline & & $2, \ldots, 25$ & 0.58 \\
\hline & & $1, \ldots, 12,14, \ldots, 25$ & 0.58 \\
\hline & \multirow{3}{*}{125} & $1, \ldots, 24$ & 0.6 \\
\hline & & $2, \ldots, 25$ & 0.6 \\
\hline & & $1, \ldots, 12,14, \ldots, 25$ & 0.6 \\
\hline & \multirow{3}{*}{250} & $1, \ldots, 24$ & 0.6 \\
\hline & & $2, \ldots, 25$ & 0.6 \\
\hline & & $1, \ldots, 12,14, \ldots, 25$ & 0.6 \\
\hline
\end{tabular}

Table 8 The discount factor $\Delta$ for $p=25$ player games. For any $\delta<\Delta$, the equilibrium shares for the players in $\left\{A_{1}\right\} \cup Z$ decrease monotonically as we go down the agenda from the first to the last position. For $\delta \geq \Delta$, this monotonicity is lost. 